\title{
Hyperbaric oxygen therapy alleviates vascular dysfunction and amyloid burden in an Alzheimer's disease mouse model and in elderly patients
}

\author{
Ronit Shapira1, Amos Gdalyahu1, Irit Gottfried ${ }^{1}$, Efrat Sasson ${ }^{4}$, Amir Hadanny $^{4}$, Shai Efrati ${ }^{2,3,4}$, \\ Pablo Blinder $^{1,2}$, Uri Ashery ${ }^{1,2}$ \\ ${ }^{1}$ School of Neurobiology, Biochemistry and Biophysics, The George S. Wise Faculty of Life Sciences, Tel Aviv \\ University, Tel-Aviv, Israel \\ ${ }^{2}$ Sagol School of Neuroscience, Tel Aviv University, Tel-Aviv, Israel \\ ${ }^{3}$ Sackler School of Medicine, Tel Aviv University, Tel-Aviv, Israel \\ ${ }^{4}$ Sagol Center for Hyperbaric Medicine and Research, Assaf Harofeh Medical Center, Be'er Ya'akov, Israel
}

Correspondence to: Uri Ashery; email: uria@tauex.tau.ac.il

Keywords: Alzheimer's disease, hyperbaric oxygen therapy, vascular dysfunction, cerebral blood flow, amyloid burden

Received: March 4, $2021 \quad$ Accepted: August 10, $2021 \quad$ Published: September 9, 2021

Copyright: (c) 2021 Shapira et al. This is an open access article distributed under the terms of the Creative Commons Attribution License (CC BY 3.0), which permits unrestricted use, distribution, and reproduction in any medium, provided the original author and source are credited.

\begin{abstract}
Vascular dysfunction is entwined with aging and in the pathogenesis of Alzheimer's disease (AD) and contributes to reduced cerebral blood flow (CBF) and consequently, hypoxia. Hyperbaric oxygen therapy (HBOT) is in clinical use for a wide range of medical conditions. In the current study, we exposed 5XFAD mice, a well-studied AD model that presents impaired cognitive abilities, to HBOT and then investigated the therapeutical effects using two-photon live animal imaging, behavioral tasks, and biochemical and histological analysis. HBOT increased arteriolar luminal diameter and elevated CBF, thus contributing to reduced hypoxia. Furthermore, HBOT reduced amyloid burden by reducing the volume of pre-existing plaques and attenuating the formation of new ones. This was associated with changes in amyloid precursor protein processing, elevated degradation and clearance of $A ß$ protein and improved behavior of 5XFAD mice. Hence, our findings are consistent with the effects of HBOT being mediated partially through a persistent structural change in blood vessels that reduces brain hypoxia. Motivated by these findings, we exposed elderly patients with significant memory loss at baseline to HBOT and observed an increase in CBF and improvement in cognitive performances. This study demonstrates HBOT efficacy in hypoxia-related neurological conditions, particularly in AD and aging.
\end{abstract}

\section{INTRODUCTION}

In recent years, it has become clear that vascular dysfunction is entwined in the pathogenesis of Alzheimer's disease (AD) and cognitive decline during aging [1-3]. Vascular risk factors, such as obesity, diabetes, atherosclerosis, smoking and hypertension, are major risk factors for $\mathrm{AD}$ [4]. Cerebral amyloid angiopathy (CAA), the deposition of $\mathrm{A} \beta$ peptide in cerebral vessel walls, is the most common vascular pathology in $\mathrm{AD}[5,6]$. Both $\mathrm{AD}$ and $\mathrm{CAA}$ are associated with reduced cerebral blood flow (CBF), which precedes the clinical onset of dementia [7-10] and correlates with the degree of cognitive impairment in $\mathrm{AD}[1,11]$. Accordingly, $\mathrm{CBF}$ has been proposed as a marker for disease severity [12]. Cerebral hypoperfusion [13-15] and the cerebral hypoxia that ensues $[16,17]$ have also been detected in animal models of AD. This hypoperfusion has been attributed to several mechanisms, including reduced vascular density $[18,19]$, constriction of cerebral arterioles [20, $21]$ and impaired neurovascular coupling [22, 23]. Cerebral hypoperfusion is also associated with accelerated cognitive decline $[3,24]$ and increased risk 
of dementia in the general population [2]. Therefore, developing treatments that target vascular dysfunction, as well as other $\mathrm{AD}$ pathologies, could be a promising avenue for treating the disease and improving cognitive performances in healthy elderly populations suffering from cognitive decline.

Hyperbaric oxygen therapy (HBOT), the medical administration of $100 \%$ oxygen at environmental pressure greater than one atmosphere absolute (ATA) [25], is in clinical use for a wide range of medical conditions. At present, there are only 13 FDA-approved indications for HBOT, including non-healing ischemic wounds, post radiation injuries, decompression sickness, burn repair, carbon monoxide intoxication, and diabetic ulcers [26]. In addition, there is a growing number of off-label treatments [27] like usages of HBOT to induce neuroplasticity and improve neurocognitive functions in post-traumatic brain injuries (TBI) or post-stroke patients [28, 29]. Further clinical trials that are being performed these days and additional basic scientific studies aiming to understand HBOT's mechanisms of action, will most probably expand the use of HBOT to other areas.

By increasing the dissolved oxygen content of the blood, HBOT can sustain tissues with minimal perfusion [25, 30]. Evidence from clinical studies demonstrated that HBOT induces recovery of cognitive functions in post-TBI patients $[31,32]$ by inducing cerebral angiogenesis, increasing cerebral blood flow and volume, and improving cerebral white and grey microstructures [33]. Elevation of CBF and restoration of physical abilities and cognitive functions were also shown in stroke patients [34, 35]. However, our ability to investigate the underlying mechanisms of these HBOT-mediated effects in patients is very limited. At the same time, animal models offer major advantages in advancing our understanding of the cellular and molecular mechanisms leading to increased CBF.

Recently, it was shown that HBOT improved cognitive performance in animal models of Alzheimer's disease $[17,36]$, and improved the metabolic status and cognitive scores of $\mathrm{AD}$ and amnestic mild cognitive impairment patients [37-39]. However, it is not known if HBOT mitigates cerebrovascular dysfunction in AD. Therefore, we investigated the effects of HBOT on $\mathrm{CBF}$ and cognitive decline in the 5XFAD mouse model of $\mathrm{AD}$ that presents aggressive accumulation of amyloid load [40], cerebrovascular abnormalities [15, 41, 42] and cognitive impairment [40], as well as in elderly individuals suffering from significant memory loss. We report that HBOT improves $\mathrm{CBF}$ and cognitive function in both $\mathrm{AD}$ mice and elderly patients with significant memory loss. HBOT elevated $\mathrm{CBF}$ and reduced cerebral hypoxia by increasing blood vessel diameter. Furthermore, by tracking single plaques in vivo over weeks, we show for the first time that HBOT reduces the volume of pre-existing plaques and the appearance of newly-formed plaques.

\section{RESULTS}

\section{HBOT reduces the amyloid load of 5XFAD mice by reducing the number of newly-formed plaques and decreasing the volume of existing plaques}

We first asked if increasing oxygen delivery to the brain by administrating HBOT reduced amyloid burden. To that end, we employed a custom-made HBO chamber to expose 6 month-old 5XFAD and wild type (wt) mice to HBOT at 2 ATA for 60 minutes per day, 5 days a week for 4 weeks (i.e., 20 treatments). To assess the effect of HBOT on amyloid burden in the treated 5XFAD mice, brains were stained with anti-A $\beta$ pan-antibodies (4G8, directed against epitope 17-24; Figure 1). We found significant reduction in amyloid burden in the hippocampus of HBO-treated 5XFAD mice, as manifested by the reduced percentage of hippocampal area displaying 4G8 immunoreactivity $(-54.32 \%$, $P=0.0353$; Figure 1A, 1B), decreased numbers of plaques $(-31.58 \%, P=0.0217$; Figure 1C) and smaller plaque size $(-18.94 \%, P=0.0125$ by Welch's correction; Figure 1D), relative to control 5XFAD mice exposed to normobaric conditions.

We then analyzed the levels of soluble (TBS fraction) and insoluble (Formic Acid fraction) levels of $A \beta 42$ and $\mathrm{A} \beta 40$ in the hippocampus by ELISA (Figure 1E, 1F). Following 1 month of HBOT, levels of insoluble A $\beta 42$ were reduced by $\sim 56 \%$ (FA fraction, $P=0.0292$ by Welch's correction; Figure $1 \mathrm{~F}$ ), while $\mathrm{A} \beta 40$ levels were reduced by $\sim 45 \%$ (FA fraction, $P=0.0356$; Figure $1 \mathrm{~F}$ ) in HBO-treated 5XFAD mice compared with control 5XFAD mice. In contrast, soluble $A \beta 42$ and $A \beta 40$ levels were unchanged (TBS fraction; Figure 1E). Collectively, these data demonstrate that HBOT reduced the amyloid load in the hippocampal formation of 5XFAD mice.

To study the dynamics of plaque formation and growth in vivo, we addressed changes in amyloid plaques before and after HBOT of the same mice by performing longitudinal in vivo two-photon imaging via introduction of a cranial window over the barrel cortex [43]. We then stained amyloid plaques in vivo with methoxy-X04 and imaged the same $A \beta$ plaques before and after one month of exposure to HBOT or control conditions. Initially, we investigated whether HBOT affected the volume of preexisting plaques by tracing the volume of single plaques before and after each treatment in the same animals (Figure 2A, 2B). 
We classified pre-existing plaques into sub-populations according to their initial volume (Figure 2B) and evaluated the effect of HBOT on these groups. We found that without treatment, small pre-existing plaques ranging in volume from $2-800 \mu \mathrm{m}^{3}$ exhibited a greater increment in volume (2.83-fold) than did larger preexisting plaques. Larger plaques, with volumes ranging 801-2000 $\mu^{3}$ (medium-sized plaques) showed only a
A
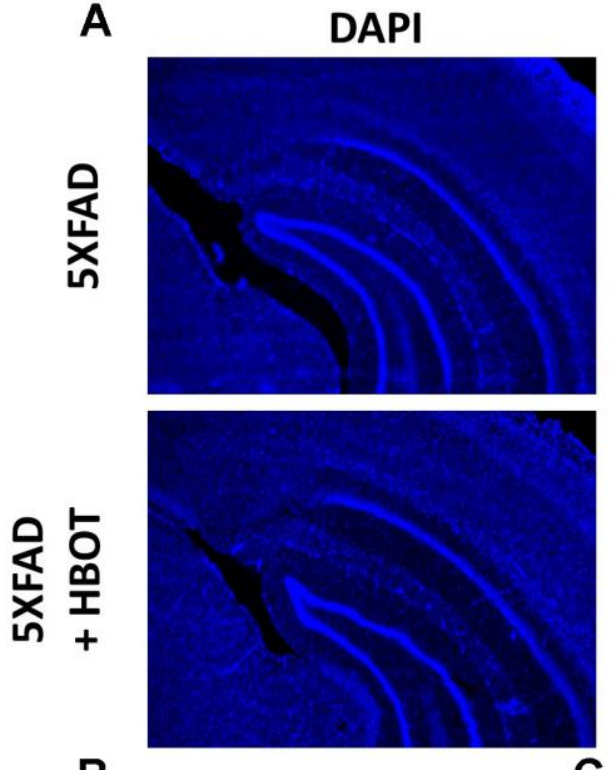

B

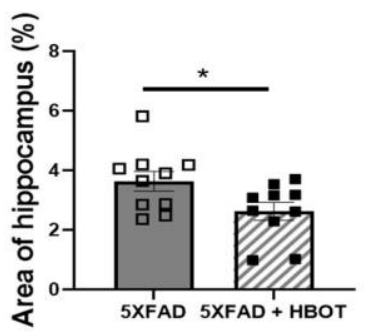

$A \beta$
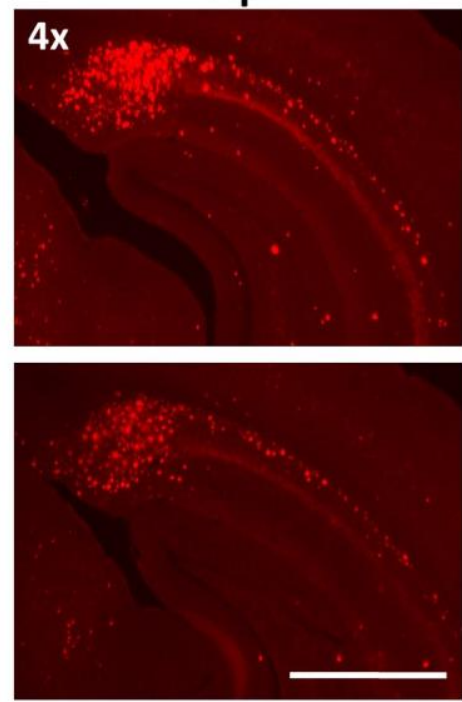

C

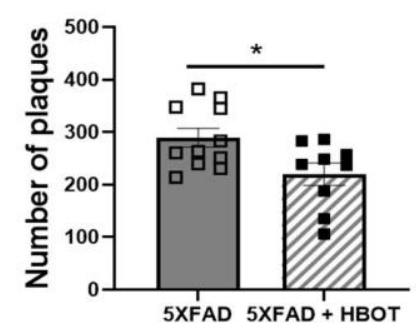

$A \beta$
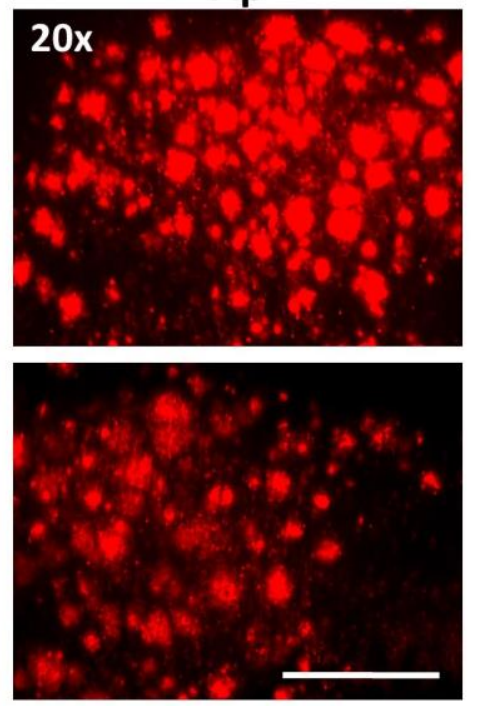

.

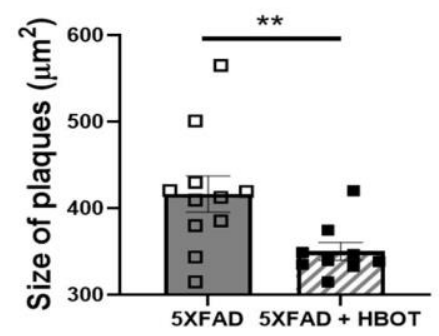

E

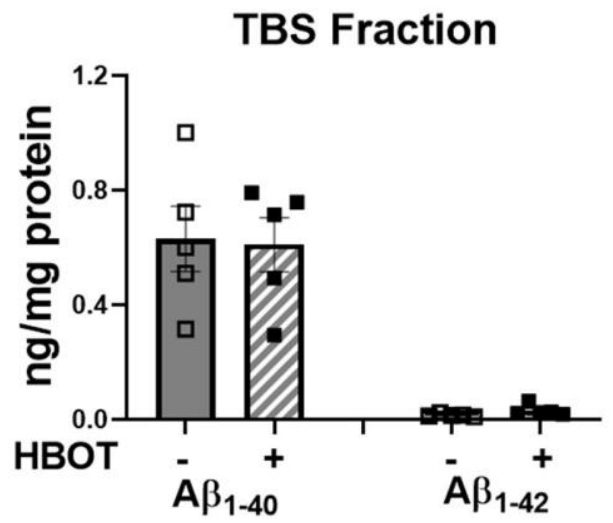

$\mathbf{F}$

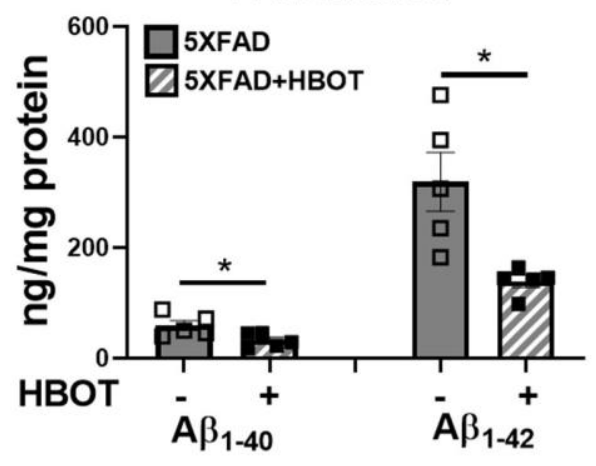

Figure 1. HBOT reduces amyloid plaques in the hippocampal area of 6-month old 5XFAD mice. Amyloid plaques were visualized by immunostaining with anti-A $\beta$ antibodies (4G8). (A) Representative images of $A \beta$ in the hippocampal field of HBO-treated 5XFAD ( $n=10$, lower panel) and control 5XFAD mice ( $n=10$, upper panel); left and middle panels, $x 4$ magnification, scale bar: $1000 \mu \mathrm{m}$; right panel, $\mathrm{x} 20$ magnification, scale bar: $200 \mu \mathrm{m}$. (B) Quantification of the percentage of hippocampal area occupied by plaques. (C) Number of plaques. (D) Mean size of plaques. (E, F) Soluble $A \beta$ was initially extracted from hippocampi with TBS by ultracentrifugation and then insoluble $A \beta$ was extracted with $70 \%$ formic acid (FA) after ultra-centrifugation. ELISA analysis of soluble (E) and insoluble (F) $A \beta 40$ and $A \beta 42$ in hippocampal lysates of HBO-treated 5XFAD and control 5XFAD mice ( $n=5$ /group). (B, C, F) -t-test, (D, F)- welch correction t-test. Values represent means \pm SEM. ${ }^{*} P<0.05, * * P<0.01$. 


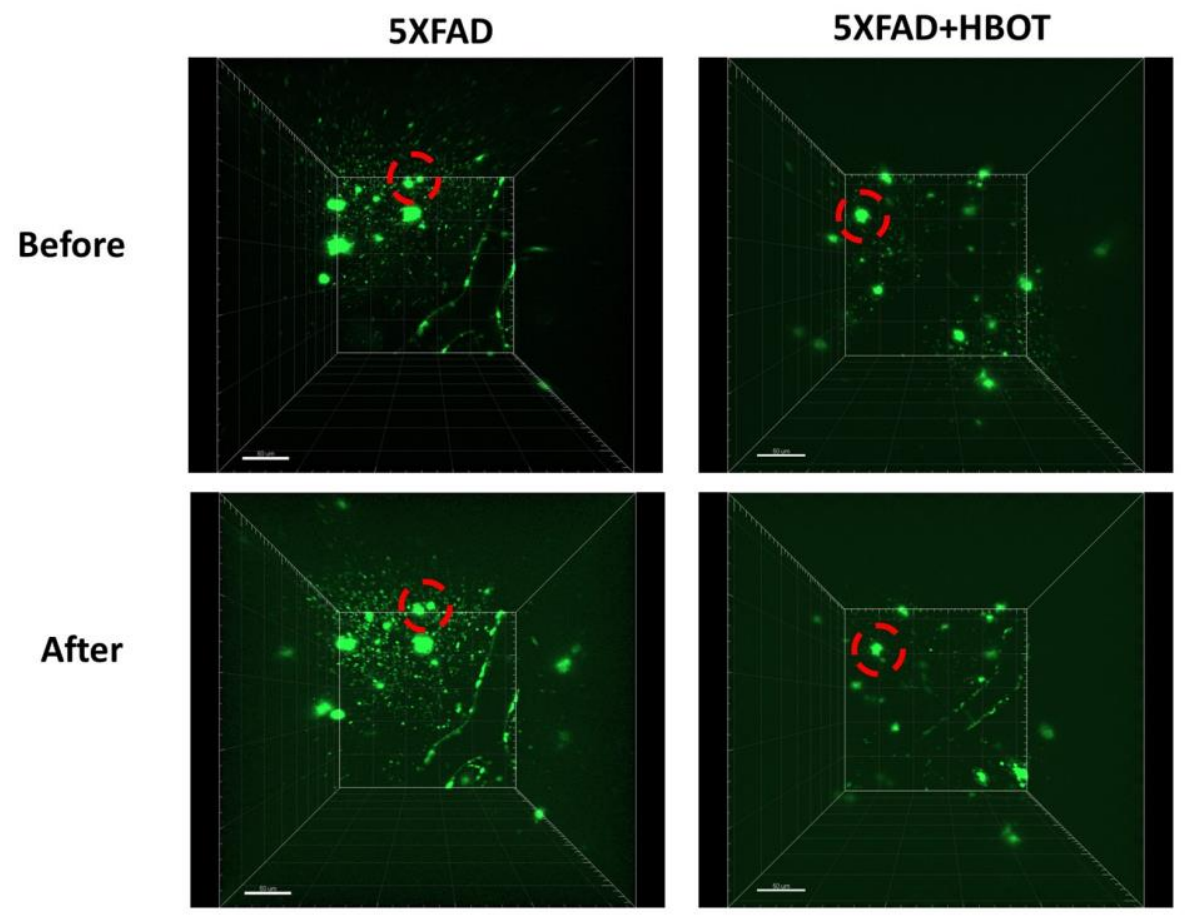

Pre-existing plaques

B $0-800 \mu \mathrm{m}^{3}$
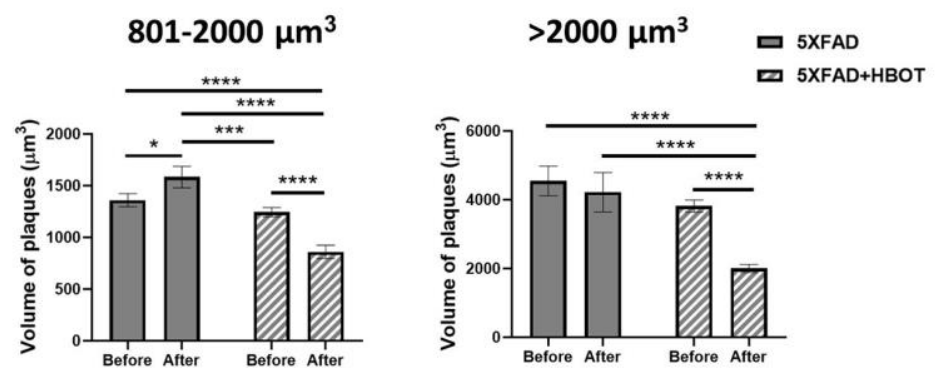

C

D

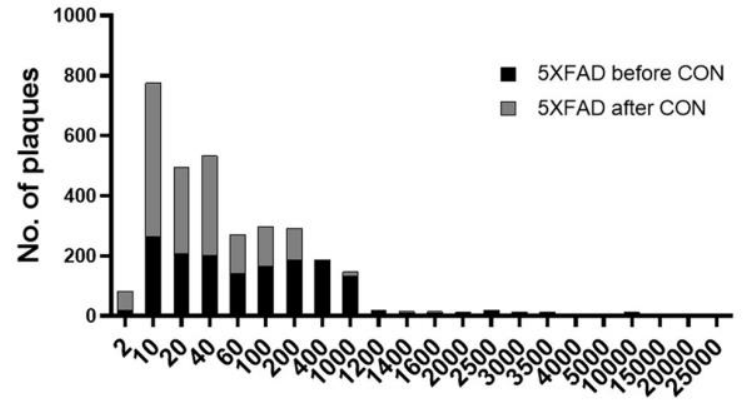

Volume $\left(\mu \mathrm{m}^{3}\right)$

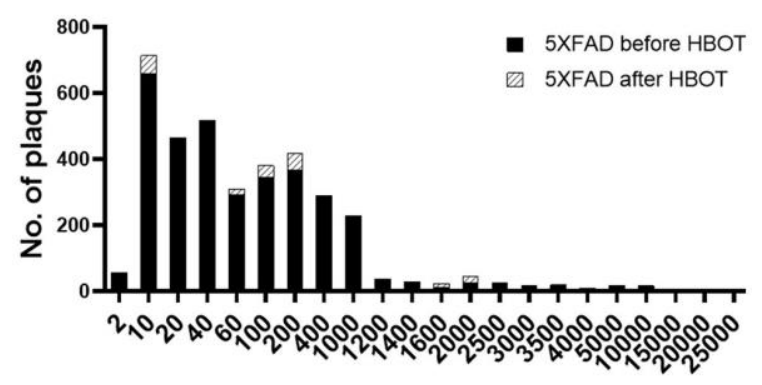

Volume $\left(\mu \mathrm{m}^{3}\right)$

Figure 2. HBOT reduces the population of newly-formed plaques and reduces the volume of pre-existing plaques. Amyloid plaques were visualized in vivo using two-photon microscopy imaging in live animals by injecting methoxy-X04 $24 \mathrm{~h}$ before every imaging session. (A) Representative images of plaques in the somatosensory cortex of HBO-treated 5XFAD ( $n=4$, right panel) and control 5XFAD mice ( $n=3$, left panel) before (upper panel) and after 1 month of treatment (lower panel); red circles indicate the change in specific plaques, scale bar: $50 \mu \mathrm{m}$. (B) Analysis of the volume of pre-existing plaques before and after each treatment in the same animal, categorized according to initial plaque size. (C, D) Distribution of plaque populations by volume in control 5XFAD (C; before: N=1619, after: N=3180) and HBO-treated 5XFAD mice ( $D$; before: $N=3425$, after: $N=3524)$. Two-way ANOVA with repeated measures and post-hoc Fisher LSD tests were performed. Values represent means \pm SEM. $* P<0.05, * * * P<0.001, * * * * P<0.0001$. 
1.17-fold increase and plaques with sized $>2001 \mu \mathrm{m}^{3}$ (large plaques) showed no increase in volume (Figure 2B). This is in accordance with previous studies that demonstrated that smaller plaques present a higher rate of increased volume, relative to larger plaques in $\mathrm{AD}$ models $[44,45]$. Strikingly, HBOT halted the significant increase in volume of the small pre-existing plaques $(P=0.3387$; Figure 2B, left panel) and facilitated reductions in the volumes of medium-sized $(P<0.0001$; Figure $2 \mathrm{~B}$, middle panel) and large plaques $(P<0.0000001$, Figure $2 \mathrm{~B}$, right panel). It should be noted that the initial averaged volume of pre-existing plaques was similar between treatment groups at all volume ranges (Figure 2B), yet HBOT had differential effects on the growth of smaller plaques and the breakdown of larger plaques. Averaging all plaque sizes uncovered that in control 5XFAD mice, existing plaques increased in size by $12.3 \%$ on average over 1 month $(P=0.0499)$, while existing plaques in HBOtreated 5XFAD mice decreased by $40.05 \%$ on average $(P$ $<0.001$, two-way ANOVA with repeated measures) (data not shown).

We next analyzed the total number of plaques to learn about pre-existing and novel plaques and found that in 5XFAD mice the number of plaques nearly doubled over the course of one month (1.96-fold change), suggesting that high and rapid synthesis of newlyformed plaques had occurred (Figure 2C). However, in HBO-treated 5XFAD mice, the number of plaques was unchanged over the same period (1.03-fold change; Figure 2D). Assessing the distribution of plaque volumes revealed that while there was a dramatic increase in that plaque population with volumes ranging from 2-400 $\mu^{3}$ in control 5XFAD mice over the course of a month, in HBO-treated 5XFAD mice, the distribution of plaque volumes did not change during a month of treatment (Figure 2C, 2D).

Taken together, these results suggest that HBOT both attenuates the appearance of newly- formed plaques and causes a reduction in the volume of pre-existing plaques.

\section{HBOT reduces abnormal processing of amyloid precursor protein and increases levels of $\mathrm{A} \beta$ degradation and clearance}

To understand the molecular mechanisms that contribute to the observed reduction in amyloid burden, we next assessed key proteins involved in amyloid precursor protein (APP) processing, and $\mathrm{A} \beta$ degradation and clearance. First, levels of the $\beta$-secretase-cleaved Cterminal fragment of APP ( $\beta$-CTF or C99) and the $\alpha-$ secretase-cleaved C-terminal fragment of APP $(\alpha-$ CTF or C83) were measured [46]. HBO treatment significantly reduced $\mathrm{C} 99$ levels in 5XFAD mice
$(-40.41 \%, P=0.0060$; Figure 3A, 3B) and induced no change in levels of the $\mathrm{C} 83$ fragment in 5XFAD mice $(P=0.7198$; Figure 3A, 3C), suggesting that HBOT reduced $\beta$-secretase (BACE1)-mediated cleavage of APP. Indeed, BACE1 levels were found to be reduced in the HBO-treated mice (Supplementary Figure 1C, 1D). As we previously showed with the $3 \times \mathrm{Tg}$ mouse model [17], the levels of full-length APP were also unchanged upon HBO treatment of 5XFAD mice (Supplementary Figure 1A, 1B), whereas the levels of the $\alpha$-secretase ADAM10 were reduced by HBOT (Supplementary Figure 1C-1E). In addition, while the levels of presenilin 1 (PSE), a component of the $\gamma$ secretase complex, were also significantly reduced in 5XFAD mice following HBOT (Supplementary Figure $1 \mathrm{C}-1 \mathrm{E})$, no changes were found in the levels of nicastrin, another component of the $\gamma$-secretase complex (Supplementary Figure 1C, 1E).

HBOT has been shown to affect microglial function and increase $A \beta$ clearance, thus contributing to neuroprotection [17, 47]. Analysis of plaqueassociated microglia showed that following HBOT, the number of microglia per plaque increased, suggesting that HBOT induced microglial recruitment to the plaques, possibly supporting plaque degradation (Supplementary Figure 1F).

We next examined whether HBO treatment affects insulin-degrading enzyme (IDE), a key enzyme responsible for the degradation of $\mathrm{A} \beta$ peptides [48]. IDE levels were significantly increased in HBO-treated 5XFAD mice, as compared to controls $(+72.58 \%, P=$ 0.009; Figure 3D, 3E), suggesting that HBOT increased $\mathrm{A} \beta$ degradation. Low density lipoprotein receptorrelated protein 1 (LRP1) plays a role in clearing $A \beta$ from the brain, across the blood-brain barrier and into the systemic circulation $[49,50]$ or clearing $A \beta$ from the parenchyma into neurons [51] and astrocytes [52]. LRP1 levels were significantly increased in HBOtreated 5XFAD mice, as compared to controls $(+65.16 \%, P=0.0008$; Figure $3 \mathrm{~F}, 3 \mathrm{G})$, suggesting that HBOT increases $\mathrm{A} \beta$ clearance.

Taken together, these results suggest that HBOT attenuates amyloid burden by reducing $A \beta$ synthesis via a decrease in APP-cleaving enzymes and by enhancing $\mathrm{A} \beta$ elimination via increased activities of degradation and clearance pathways.

\section{HBOT alleviates the reduction in vessel diameter and increases blood flow and arteriolar lumen size in 5XFAD mice}

Abnormalities in microvessels found near $\mathrm{A} \beta$ plaquedeposited areas in 5XFAD mice contribute to reduced 
CBF [15]. To gain insight into the effects of HBOT on $\mathrm{CBF}$, we used in vivo two-photon microscopy to address the cortical vasculature of the same mouse before and after a month of exposure to HBOT or control conditions (Figure 4). Such analysis revealed that in control 5XFAD mice, there was significant reduction in vessel diameters over the course of the month $(-8.57 \%, P=0.0002$, paired t-test; Figure 4A, $4 \mathrm{~B})$. In contrast, no significant reduction in blood vessel diameters was observed in HBO-treated 5XFAD mice ($0.53 \%$, Figure 4A, 4B, $P=0.2206$, paired t-test). The fold change in vessel diameters showed a downward trend in the control group, as compared to the HBOtreated group $(P=0.0601$, t-test; Figure 4B).

To measure blood flow velocity in specific blood vessels, the vascular serum was labeled with a fluorescent dye (FITC) conjugated to high molecular weight dextran to prevent dye leakage from the vasculature. The velocities of non-fluorescent red blood cells (RBCs) were then tracked on this fluorescent background by tracing RBC movement over distance and time [53, 54]. RBC velocity was elevated following one month of HBOT, as compared to control normobaric conditions, yet not significantly (control: $2.70 \%$; HBOT: $+54.89 \%$; fold change $P=0.0652$, ttest; Figure 4C). However, RBC flow, which provides a complete description of blood flow in each vessel, showed significant improvement following HBOT (control: $-20.35 \%$, HBOT: $+82.82 \%$; fold change $P=$ 0.014 , t-test; Figure 4D). These results directly show that HBOT alleviated reductions in blood vessel diameter, and, therefore, contributed to increased blood flow in 5XFAD mice.

A
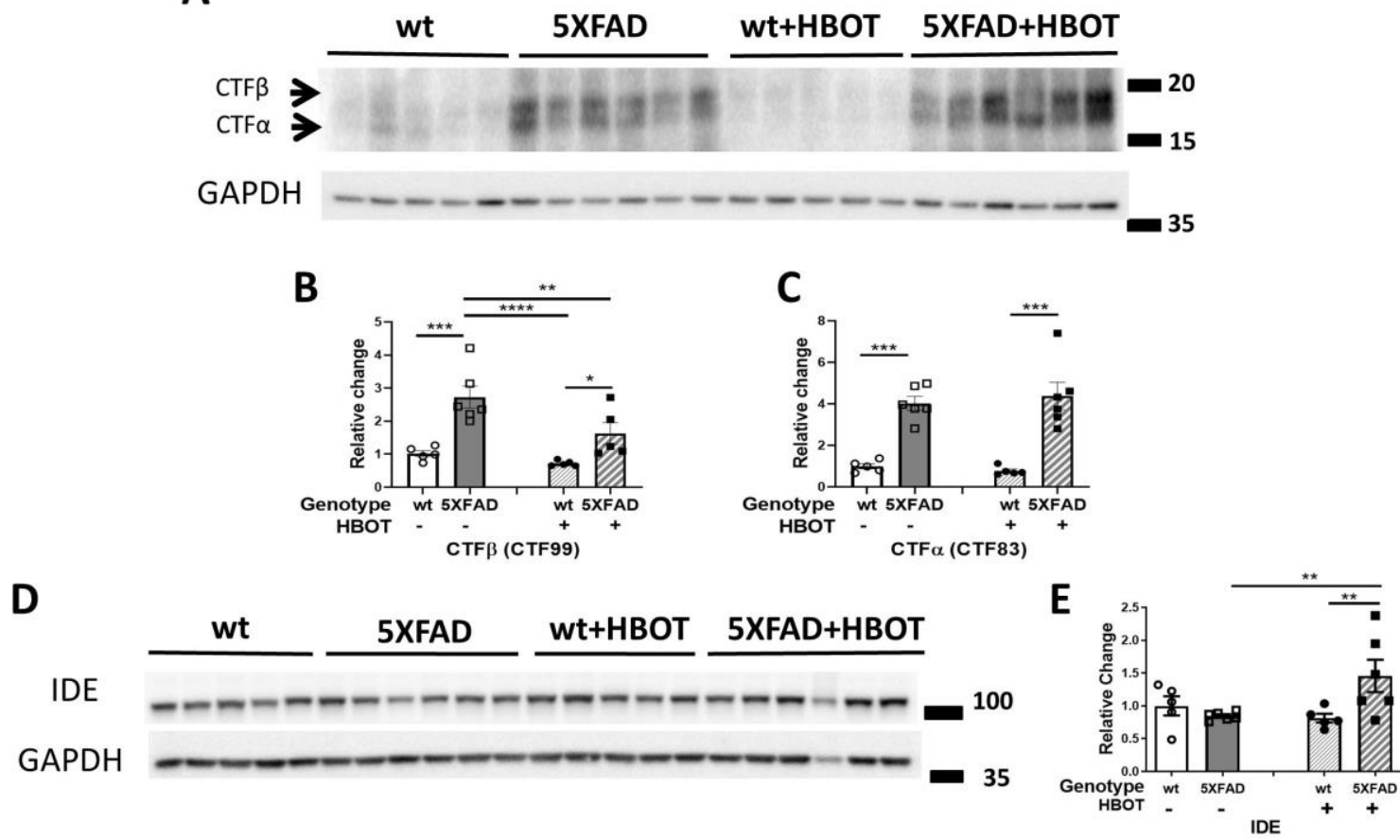

$\mathbf{F}$
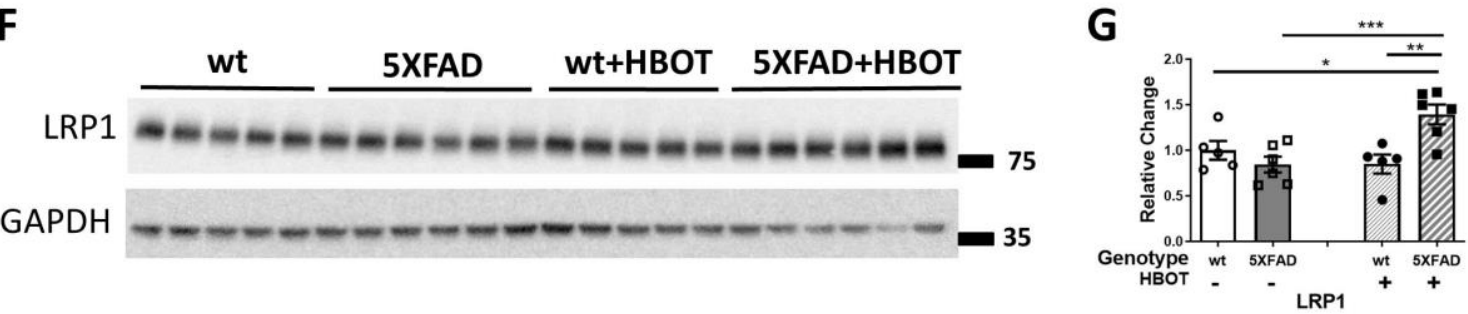

Figure 3. HBOT reduces abnormal processing of APP and attenuates A $\beta$ degradation and clearance in 5XFAD mice. (A) Representative immunoblot assays of the carboxyl-terminal fragment (CTF) $\beta$ and CTF $\alpha$. (B, C) Quantification of western blots in (A), presented as percentages of wt control, normalized to GAPDH levels ( $n=5-6 /$ group). (D-G) Representative immunoblot assays of IDE protein (D) and LRP1 in (F). (E, G) Quantification of western blots in (D, F), respectively, presented as percentages of wt controls, normalized to GAPDH levels ( $n=5-6 /$ group). Two-way ANOVA and post-hoc Fisher LSD tests were performed. Values represent means \pm SEM. $* P<0.05, * *$ $P<0.01, * * * P<0.001, * * * * P<0.0001$. 
Finally, we double-stained the vasculature using antibodies raised against anti-smooth muscle actin antibody ( $\alpha$-SMA antibody) and A $\beta$ (4G8 antibody) and measured arteriolar wall thickness, luminal diameter and the $\mathrm{A} \beta$ area around arterioles in hippocampal and cortical areas in the brains of mice exposed to HBOT or normobaric conditions (Figure 5). In both the hippocampal and cortical areas, SMA staining revealed that control 5XFAD mice displayed decreased luminal diameters (hippocampus: $-11.22 \%, P=0.0107$; cortex: $17.14 \%, P=0.0407$; Figure 5A, 5B, 5F, 5G, respectively), higher arteriolar wall thickness (hippocampus: $+19.75 \%, P=0.0308$; cortex: $+31.74 \%$,
$P=0.0077$; Figure 5A, 5C, 5F, 5H, respectively), and high $\mathrm{A} \beta$ deposition around arterioles, as compared to wt mice. Similar changes were observed in AD patients, as compared to non-AD controls [55, 56]. Arteriolar luminal diameter reduction in particular has been suggested to play a role in cerebral hypoperfusion during AD progression [56]. Following HBOT, the luminal diameter was greatly increased in both hippocampal $(+13.798 \%, P=0.016$; Figure 5A, 5B) and cortical areas $(+25.59 \%, P=0.0064$; Figure 5F, $5 \mathrm{G}$ ) of HBO-treated 5XFAD mice, as compared to control mice. HBO treatment did not change arteriolar wall thickness of 5XFAD mice in
A

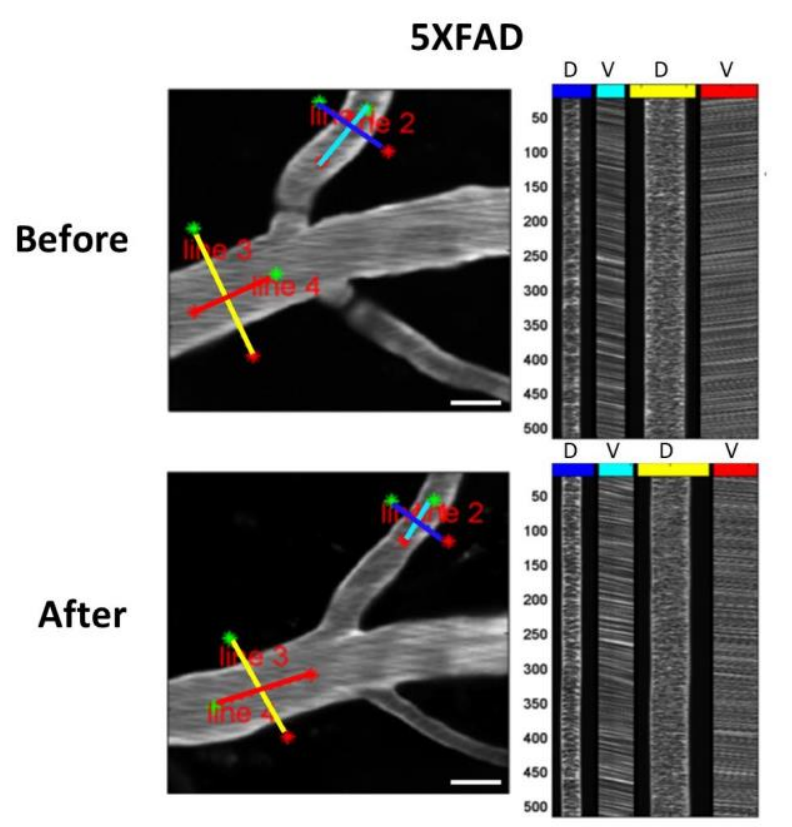

B

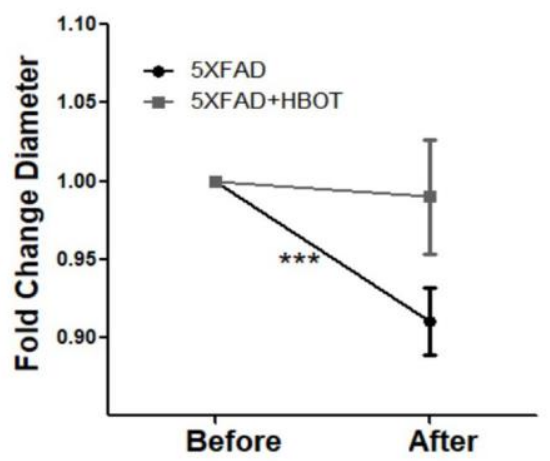

C

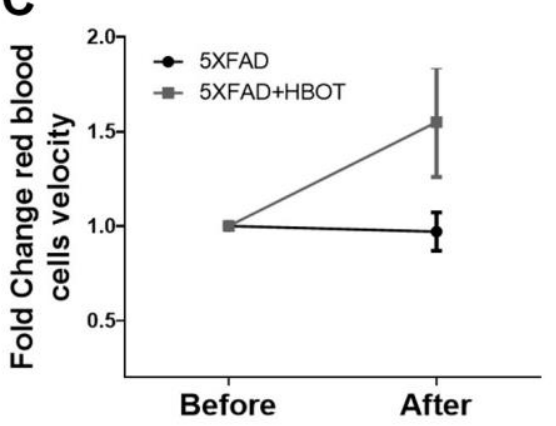

5XFAD+HBOT

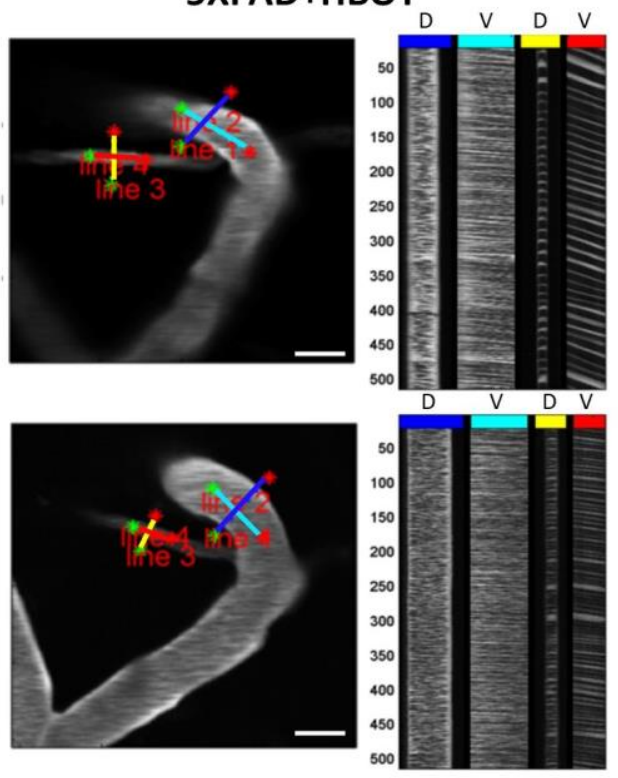

D

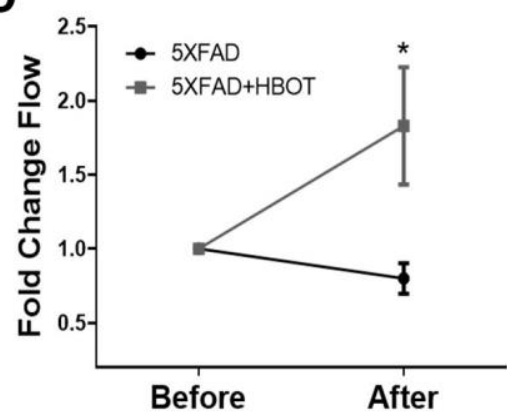

Figure 4. HBOT alleviates the reduction in vessel diameter in 5XFAD mice and increases blood flux. In vivo two-photon microscopy imaging and measurements of diameter and velocity in blood vessels of the somatosensory cortex in 5XFAD mice using spatially optimized line scans. (A) Representative images of fluorescently stained vessels of the somatosensory cortex of an HBO-treated 5XFAD mouse (right panel) and a control 5XFAD mouse (left panel) before (upper panel) and after a month of treatment (lower panel). Line scan patterns are superimposed on the vessels. Lines of the scan path along the length were used to calculate RBC velocity (V), while lines across the diameter of the vessels were used to calculate diameter (D). The line scans generated from the path can be stacked sequentially as a function of time to produce a raw cascade image (right of each image). Vessel diameter was calculated as the full width at half-maximum of a time average of several scans across the width of a vessel. RBC velocity was calculated from the angle of the RBC streaks. (B-D) Quantification of vessel diameter (B), RBC velocity in the blood vessels (C) and RBC flow (D), normalized to each treatment group baseline value. Paired t-tests and student t-tests were performed. Values represent means \pm SEM. $* P<0.05, * * * P<0.001$. 
hippocampal areas $(P=0.4387$; Figure $5 \mathrm{~A}, 5 \mathrm{C})$, yet caused a decrease in wall thickness in cortical areas of treated 5XFAD mice, as compared to control mice $(-16.56 \%, P=0.0477$; Figure 5F, 5G). Finally, no changes were measured in $\mathrm{A} \beta$ deposition around arterioles in both hippocampal (Figure 5D, 5E) and cortical areas (Figure 5I, 5J) following HBOT. These findings corroborate our in vivo imaging results showing a narrowing of blood vessels in 5XFAD mice over a month (Figure 4) and suggest a mitigating effect of HBOT on vascular parameters. Collectively, these results suggest improved blood perfusion following HBOT.
HBOT reduces hypoxia and hypoxia inducible factor-1 (HIF-1) levels in 5XFAD mice

We next investigated whether the changes in $\mathrm{CBF}$ following HBOT reduced hypoxia in the hippocampal area of 5XFAD mice. Fourteen days following the last session of $\mathrm{HBO}$ or control treatment, mice were injected with Hypoxyprobe, a label which is only activated and detectable in hypoxic cells, characterized by a partial pressure of oxygen below $10 \mathrm{~mm} \mathrm{Hg}(<1 \%)$. As can be seen in Figure 6, the 5XFAD control mice showed increased reactivity of Hypoxyprobe in hippocampal areas CA3 (3.69-fold
A
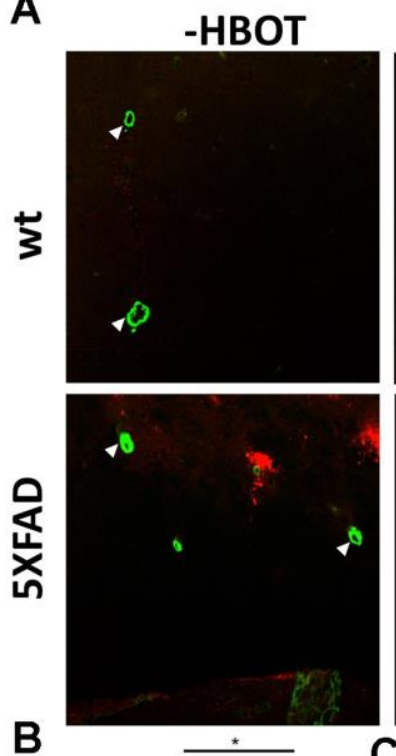

B

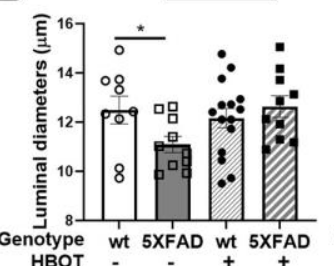

D

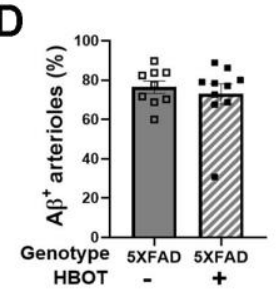

$+\mathrm{HBOT}$
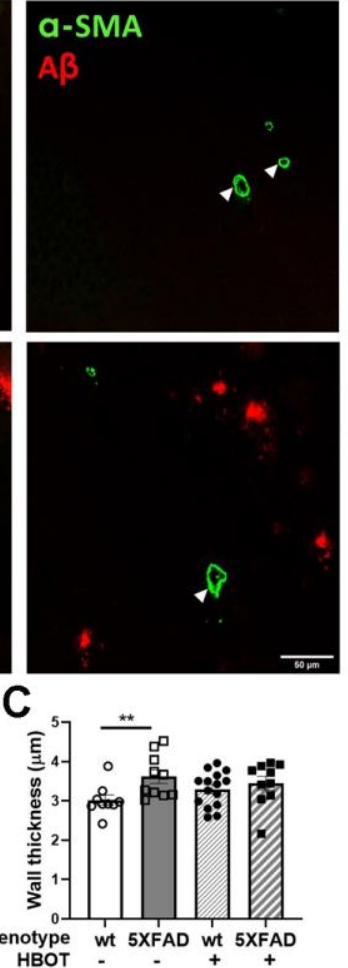

E

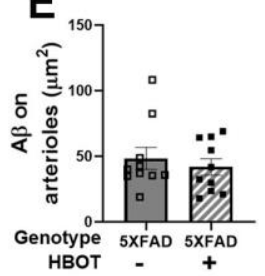

$\mathbf{F}$
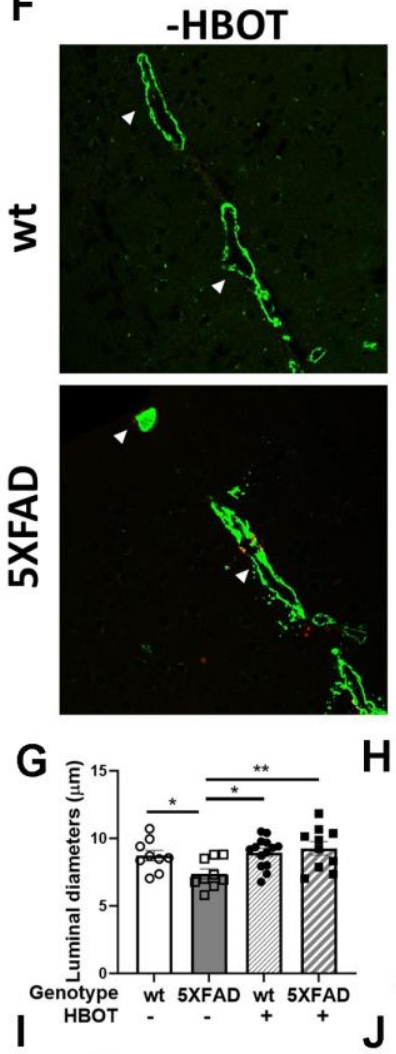

$\mathrm{H}$

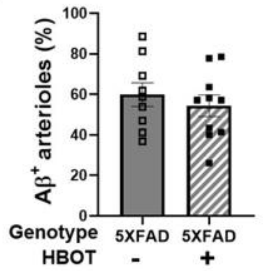

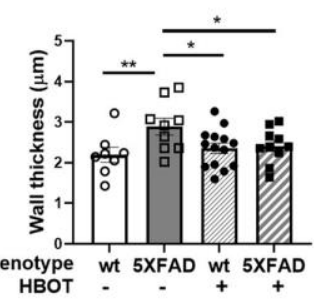

$+\mathrm{HBOT}$

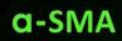

$A \beta$
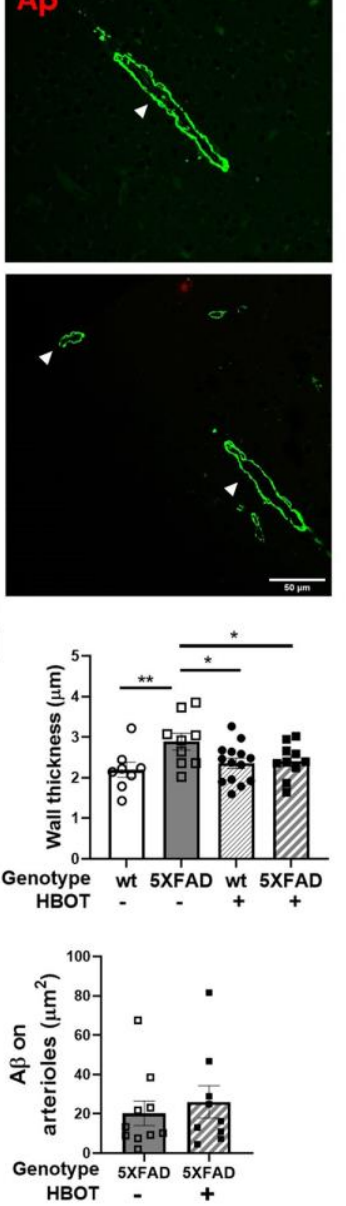

Figure 5. HBOT attenuates arteriolar luminal diameter but not amyloid deposition around arterioles in 6-month old 5XFAD mice. Arterioles were visualized using immunostaining with anti-SMA antibody while vascular amyloid deposition was visualized using anti$A \beta$ antibody (4G8). (A, F) Representative images of arterioles and $A \beta$ in hippocampal (A) and cortical fields (F) of $H B O$-treated wt ( $n=9$, upper right panels) and 5XFAD mice ( $n=10$, lower right panels) and control wt ( $n=9$, upper left panels) and 5XFAD mice ( $n=10$, lower left panels) (x40 magnification, scale bar: $50 \mu \mathrm{m})$. White arrows show hippocampal and cortical arterioles. (B-E) and (G-J), Quantification of arteriolar luminal diameters $(\mathbf{B}, \mathbf{G})$, arteriolar wall thickness $(\mathbf{C}, \mathbf{H})$ and percentages of arterioles that stained positive for $A \beta(\mathbf{D}, \mathbf{I})$ and $A \beta$ deposition area around arterioles (E, J) in the hippocampal (B-E) and cortical fields (G-J). Two-way ANOVA and post-hoc Fisher LSD tests were performed. Values represent means \pm SEM. $* P<0.05, * * P<0.01$. 
increase, $P=0.0076$; Figure 6A, 6B) and CA1 (8.19fold increase, $P=0.0021$; Figure 6A, 6C), as compared with the same areas in their wt counterparts. Remarkably, HBOT significantly reduced the reactivity of Hypoxyprobe in the hippocampal formation of 5XFAD mice in both CA3 (3.11-fold decrease, $P=0.0145$; Figure 6A, 6C) and CA1 (2.48fold decrease, $P=0.0261$; Figure $6 \mathrm{~A}, 6 \mathrm{C}$ ), relative to 5XFAD control mice.

To corroborate our finding and identify the molecular pathway affected by HBOT, levels of the oxygen

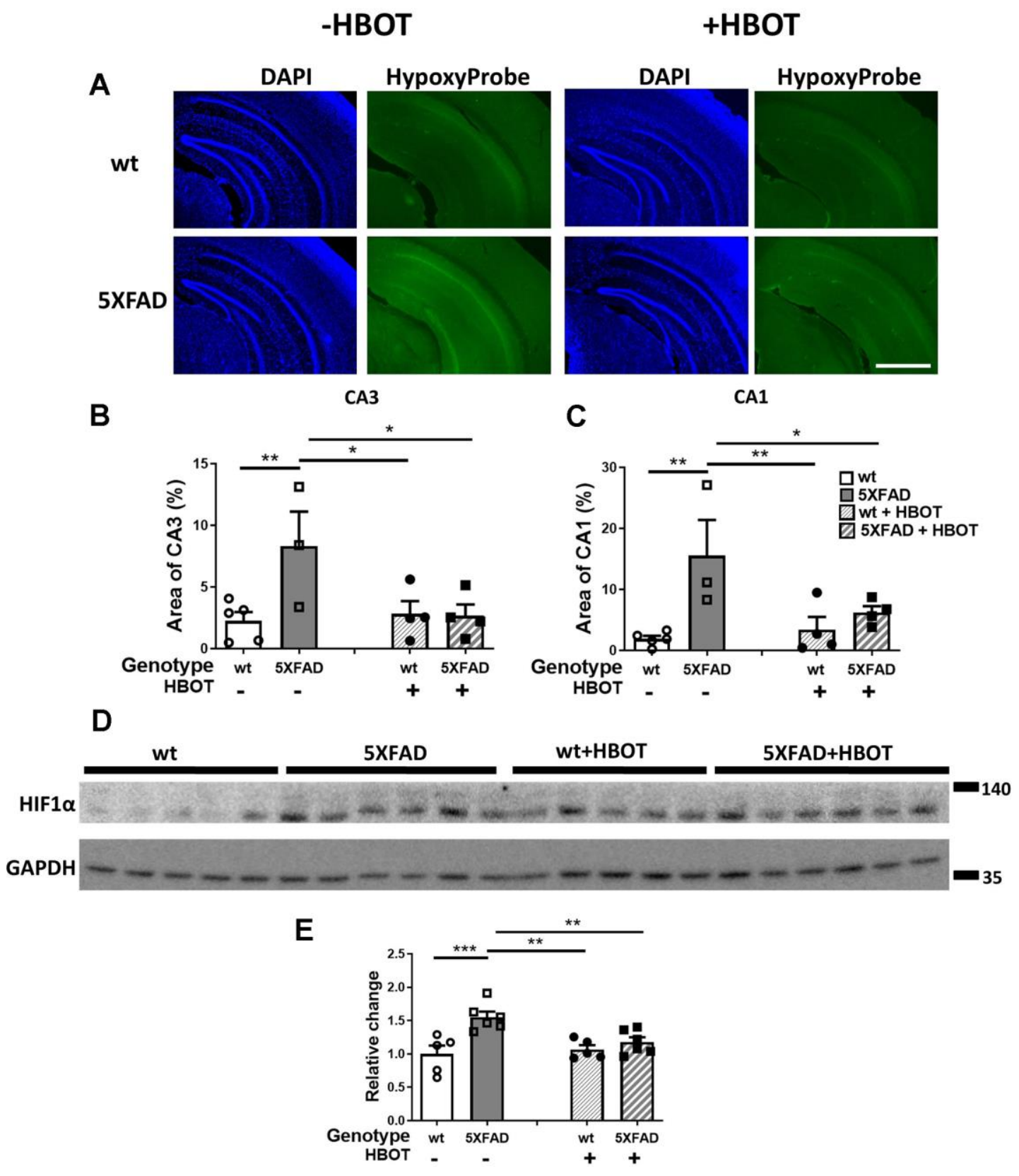

Figure 6. HBOT reduces hypoxia and HIF1 $\alpha$ transcription factor levels in the hippocampal area of 6-month old 5XFAD mice. (A) Uptake of Hypoxyprobe by low oxygen-bearing cells was visualized by immunostaining. Representative images of the presence of hypoxia in the hippocampal field of HBO-treated $w t(n=4$, right upper panel) and 5XFAD mice ( $n=4$, right lower panel), and control wt ( $n=5$, left upper panel) and 5XFAD mice ( $n=3$, left lower panel); x4 magnification, scale bar: $1000 \mu \mathrm{m}$. (B, C) Quantification of the percentage of the CA3 (B) and CA1 (C) areas presenting Hypoxyprobe-related fluorescence. (D) Western blots of HIF-1 $\alpha$ from hippocampi extracted from HBO-treated and control 5XFAD mice and wt littermates. (E) Quantification of Western blots in (D), presented as percentage of wt control, normalized to GAPDH levels ( $n=4-5 /$ group). Two-way ANOVA and post-hoc Fisher LSD tests were performed. Values represent means \pm SEM. $* P<0.05$, $* * P<0.01, * * * P<0.001$. 
tension-dependent transcriptional factor hypoxia inducible factor-1 (HIF-1) were tested. Under normoxic conditions, HIF- $1 \alpha$ is degraded. However, under hypoxic conditions, HIF1 $\alpha$ is stabilized and its levels are increased [57]. HIF1 $\alpha$ levels increased in 5XFAD mice, as compared to wt littermates $(+55.17 \%, P=$ 0.0003 ; Figure 6D, 6E). HBOT significantly reduced HIF $1 \alpha$ levels in 5XFAD mice $(-24.12 \%, P=0.0056$; Figure 6D, 6E). Taken together, these experiments indicate a high degree of hypoxia in the hippocampal area of 5XFAD mice that can be significantly reduced by HBOT. Furthermore, these results demonstrate that HBOT reduced the hypoxic state in 5XFAD mice even 14 days after the last $\mathrm{HBO}$ session, suggesting that HBOT induced a long-lasting effect by increasing arteriolar lumen volume and elevating blood flow.

\section{HBOT improves the performance of 5XFAD mice in behavioral tasks}

Finally, we explored if the mitigating effects of HBO treatment on $\mathrm{AD}$ pathology are associated with an improvement in the performance of 5XFAD mice in behavioral tasks. We found that HBO-treated 5XFAD mice showed improved nest construction abilities, given how they built nests with higher walls and attained higher nest scores (Supplementary Figure 2). Moreover, the treated mice showed improved exploratory behavior, as compared to control 5XFAD mice (Supplementary Figure 2).

Spatial recognition memory was investigated by testing the natural preference of mice for exploring novel over familiar spatial contexts in a Y-maze test (Figure 7A). Control 5XFAD mice showed a decreased time index in this assay, as compared to their wt littermates (wt control: $0.7367 \pm 0.02168$ vs. $5 X F A D$ control: $0.5596 \pm$ $0.03382, P=0.00013$; Figure 7A), HBOT significantly reversed this trend (5XFAD-HBO: $0.6572 \pm 0.03378$ vs. 5XFAD-control: $0.5596 \pm 0.03382, P=0.0362$; Figure 7A). We then tested the effect of HBOT on hippocampus-dependent contextual memory by performing trace fear conditioning [58-60]. Control 5XFAD mice showed impaired contextual memory, relative to their wt littermates, as reflected by lower freezing activity in the training chamber $24 \mathrm{~h}$ following conditioning (wt control: $23.29 \pm 3.140 \%$ vs. 5XFAD control: $12.81 \pm 2.516 \%, P=0.0377$; Figure 7B). Interestingly, this impairment was recovered in HBOtreated 5XFAD mice (5XFAD-HBO: $29.10 \pm 4.321 \%$ vs. 5XFAD control: $12.81 \pm 2.516 \%, P=0.0019$; Figure 7B).

Taken together, these results suggest that HBOT ameliorated the performances of 5XFAD mice in memory and behavioral tasks.

\section{HBOT increases cerebral blood flow and improves cognitive performances in elderly patients}

To understand whether the ability of HBOT to change $\mathrm{CBF}$ and affect cognitive function also applied to elderly people, we performed a human study (NCT02790541) in which six elderly patients (age $70.00 \pm 2.68$ years) with significant memory loss at baseline (memory domain score < 100) were treated with HBOT (60 daily HBOT sessions within 3 months). $\mathrm{CBF}$ and cognitive function were evaluated before and after HBOT. CBF was measured by MRI dynamic susceptibility contrast sequential imaging, while
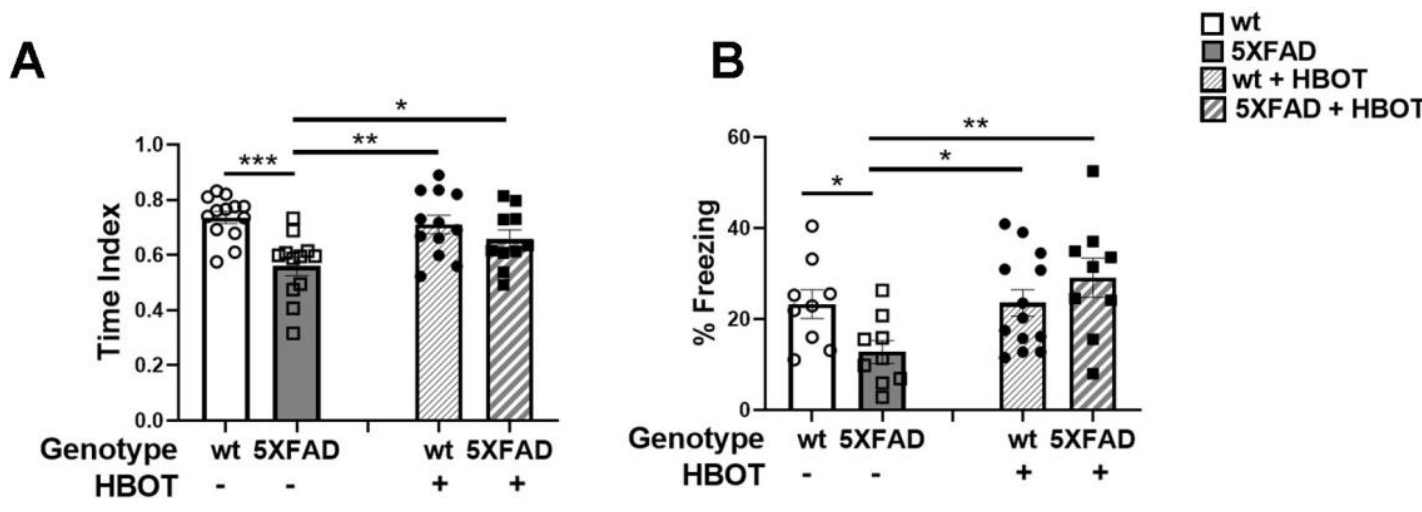

Figure 7. HBOT improves performance of 5XFAD mice in cognitive tasks. (A) In the Y-maze test, HBO-treated 5XFAD mice showed better spatial memory as reflected in the time index, which is displayed as the ratio (novel /novel + familiar) to time in each arm. (B) In the trace fear conditioning assay, mice underwent conditioning involving 6 rounds of tone-shock pairing with a trace interval. On the following day, the mice were exposed to the same context with no exposure to tone or shock. Results of contextual freezing are expressed as the percent of total time spent frozen in the training context. Two-way ANOVA with/without repeated measures and post-hoc Fisher LSD tests were performed. Values represent means \pm SEM. ${ }^{*} P<0.05,{ }^{*} p<0.01, * * * P<0.001$ 
cognitive functions were evaluated using computerized cognitive tests. Following HBOT, there were significant $\mathrm{CBF}$ increases in several brain areas, including Brodmann areas 1, 2, 32, 34, 40, 42, 43, and 48 (Figure 8A, 8B). At baseline, patients attained a mean global cognitive score (102.4 \pm 7.3$)$ similar to the average score in the general population normalized for age and education level (100), while memory scores were significantly lower $(86.6 \pm 9.2)$. Cognitive assessment following HBOT revealed a significant increase in the global cognitive score $(102.4 \pm 7.3$ to $109.5 \pm 5.8$, $\mathrm{p}=0.004$ ), where memory, attention and information processing speed domain scores were the most ameliorated (Figure 8C). Moreover, post-HBOT mean memory scores improved to the mean score $(100.9 \pm$ $7.8)$, normalized per age and education level (100). The improvements in these scores correlate with improved short and working memory, and reduced times of calculation and response, as well as increased capacity to choose and concentrate on a relevant stimulus.

Together with our findings using an AD mouse model and the similar effects observed following $\mathrm{HBO}$ treatment of stroke and TBI patients, we suggest that HBOT mediates structural changes in blood vessels that increase $\mathrm{CBF}$, reduce brain hypoxia and improve cognitive performance.

\section{DISCUSSION}

In recent decades, the development of drugs for Alzheimer's disease has primarily targeted beta amyloid and tau pathologies. However, the failures of recent clinical trials suggest that alternative strategies for $\mathrm{AD}$ treatment should be considered [61-63]. One promising alternative target is vascular dysfunction, as it is detected in the early stages of $\mathrm{AD}$, correlates with disease progression and affects disease outcome. Improved vascular function and $\mathrm{CBF}$ can also improve cognition in the elderly $[2,3,9,24,64]$. In this study, we explored this option by manipulating oxygen levels in an Alzheimer's disease mouse model and in an elderly patient population. The results revealed that increasing oxygen delivery to the brain through $\mathrm{HBO}$ treatment improved several aspects of AD pathology, including vascular dysfunction, plaque burden and behavior. HBOT-induced vascular changes also led to increased $\mathrm{CBF}$ and reduced cerebral hypoxia that continued weeks after treatment.

This study also demonstrated that HBOT improved vascular parameters in 5XFAD mice. Over the course of one month, the diameters of cortical blood vessels in these mice were reduced by $\sim 8.5 \%$ and as a result, the blood flow was decreased by $\sim 20 \%$. This is in accordance with Poiseuille's model, which shows that even minimal changes in vessel diameter can have a dramatic effect on the rate of blood flow (e.g. blood vessel narrowing by $6 \%$ reduces blood flow by $22 \%$ $[65,66])$. In 5XFAD mice, neutrophil adhesion led to stalled capillaries and reduced CBF [15]. Indeed, narrower vessels, as we observed, can accelerate neutrophil adhesion and lead to stalled capillaries. HBOT alleviated the thinning of and increased the flow of blood in cortical blood vessels. Moreover, we showed that the HBOT-induced increase in blood flow

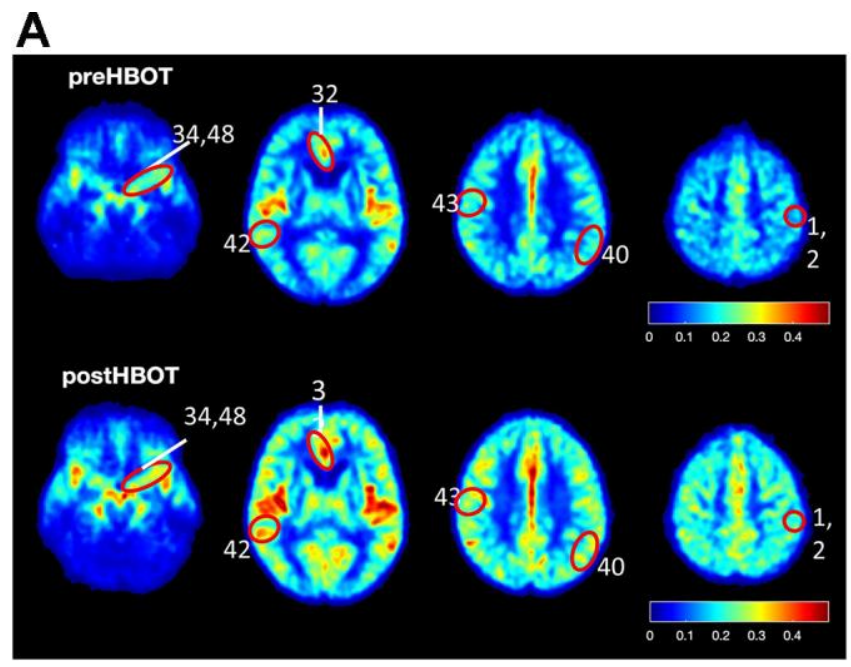

\begin{tabular}{|c|c|c|c|}
\hline & Baseline & Post HBOT & Sig. \\
\hline Brodmann $32 \mathrm{R}$ & $51.37 \pm 10.2$ & $59.85 \pm 12.24$ & 0.049 \\
\hline Brodmann 34 R & $39.74 \pm 15.76$ & $45.41 \pm 14.24$ & 0.051 \\
\hline Brodmann $42 \mathrm{R}$ & $52.47 \pm 12.10$ & $63.52 \pm 12.92$ & 0.028 \\
\hline Brodmann $43 \mathrm{R}$ & $45.55 \pm 12.63$ & $55.85 \pm 16.36$ & 0.038 \\
\hline Brodmann 1 L & $34.06 \pm 4.70$ & $41.13 \pm 7.76$ & 0.048 \\
\hline Brodmann $2 \mathrm{~L}$ & $37.94 \pm 4.04$ & $45.61 \pm 9.22$ & 0.042 \\
\hline Brodmann $34 \mathrm{~L}$ & $40.93 \pm 16.34$ & $47.43 \pm 15.89$ & 0.002 \\
\hline Brodmann $40 \mathrm{~L}$ & $41.03 \pm 5.73$ & $49.12 \pm 8.57$ & 0.024 \\
\hline \multirow[t]{2}{*}{ Brodmann $48 \mathrm{~L}$} & $54.52 \pm 11.68$ & $63.35 \pm 17.03$ & 0.049 \\
\hline & Baseline & Post HBOT & Sig. \\
\hline \multicolumn{4}{|l|}{ General Cognitive } \\
\hline Score & $102.43 \pm 7.35$ & $109.52 \pm 5.79$ & 0.004 \\
\hline Memory & $86.56 \pm 9.23$ & $100.88 \pm 7.78$ & 0.006 \\
\hline \multicolumn{4}{|l|}{ Executive } \\
\hline Function & $109.44 \pm 8.82$ & $110.16 \pm 10.06$ & 0.773 \\
\hline Attention & $103.93 \pm 7.48$ & $110.22 \pm 2.74$ & 0.006 \\
\hline \multicolumn{4}{|l|}{ Information } \\
\hline Processing Speed & $107.52 \pm 10.18$ & $118.68 \pm 9.99$ & 0.003 \\
\hline
\end{tabular}

Figure 8. CBF and cognitive function are improved following HBOT of patients. CBF and cognitive functions of six patients suffering from memory decline at baseline and following $60 \mathrm{HBOT}$ sessions. (A) Average normalized CBF maps (DSC) at baseline and post-HBOT. (B) Significant average CBF changes in Brodmann areas at baseline and post-HBOT. (C) Average cognitive domain scores (Neurotrax) at baseline and post-HBOT. 
was accompanied by an elevation of arteriole luminal diameters and a reduction in hypoxia in 5XFAD mice. Interestingly, reduced hypoxia was detected even 14 days after the last round of HBO treatment, suggesting that structural changes in blood vessels contribute to the reduced $\mathrm{CBF}$ of $5 \mathrm{XFAD}$ mice and that HBOT can significantly alleviate this reduction, in turn leading to reduced cerebral hypoxia. Hence, HBOT induces changes in the basic pathophysiology of the disease which last at least for 2 weeks after HBOT is completed.

Increased $\mathrm{CBF}$ and higher oxygen delivery can improve or boost brain function. HBOT induces cognitive enhancement in both young [67] and elderly healthy subjects through regional changes in CBF [68]. HBOT has also been shown to increase CBF and improve EEG measurements [34], global cognitive scores [33,69] and PET scans [70] of post-stroke and TBI patients. In the context of Alzheimer's disease, animal studies have shown that supplementation of oxygen [71, 72] or HBOT [17, 36] results in improved cognitive performance [71] and enhanced cerebral blood volume [72]. Moreover, an immediate increase in CBF due to a reduction in the number of stalled capillaries led to rapid improvement in the performance of 5XFAD mice in spatial and working memory tasks [15]. Recent human studies have shown that HBOT can improve cognitive functions of mild cognitive impairment (MCI), AD and vascular dementia patients [37-39, 73] and ameliorate the reduced brain metabolism of MCI and $\mathrm{AD}$ patients $[37,39]$. Here, we showed that HBOT increases $\mathrm{CBF}$ and improves cognitive function in elderly individuals suffering from significant memory loss, as well as increasing $\mathrm{CBF}$, alleviating cerebral hypoxia and improving behavioral deficits in 5XFAD mice. Yet, as the number of subjects in our human HBOT experiments was relatively small $(n=6)$, expanding these efforts with a larger cohort could strengthen our findings. Taken together, these data suggest that oxygen is a rate-limiting factor for both normal cognitive function and for tissue recovery in Alzheimer's disease.

Tracking plaques in the somatosensory cortex over time provided insight into the dynamics of plaques in vivo and revealed that over one month, the number of plaques in 5XFAD mice nearly doubled, with their volume increasing, suggesting that high and rapid synthesis of plaques occurs in this model. Moreover, small plaques exhibited greater size increments, relative to larger plaques. This is in agreement with other reports [44, 45, 74], although not with the work of Hefendehl et al. [75]. Remarkably, HBOT reduced the appearance of newly-formed plaques and contributed to a reduction in the size of existing medium-sized to large plaques, suggesting that HBOT affects both the synthesis of $A \beta$ and its degradation and clearance. This claim is further supported by our findings that HBOT attenuated the excessive generation of $\mathrm{A} \beta 42$ and formation of $\mathrm{A} \beta$ plaques by reducing levels of BACE1 ( $\beta$-secretase) and presenilin1 (a component of the $\gamma$ secretase), leading to reduced levels of the C-terminal $\mathrm{A} \beta$ fragment (CTF $\beta, \mathrm{C} 99)$ and of the insoluble fraction of A 442 . In addition, HBOT elevated IDE and LRP1 levels, thus promoting $A \beta$ degradation and clearance. These findings are in accordance with evidence showing that elevating either activity of the degradation pathway by enhancing IDE levels [76, 77] or of clearance pathway by changing LRP1 levels [78] leads to a reduction in amyloid burden. Our finding that the number of microglia per plaque volume increased following HBOT suggests that microglia were recruited to plaques, possibly supporting plaque degradation [79, 80]. Taken together, it seems that HBOT ameliorates the pathways of $A \beta 42$ generation, accumulation and degradation and thus contributes to the reduced appearance of novel plaques and breakdown of existing plaques.

Accumulating evidence has demonstrated that cerebral hypoperfusion and hypoxia result in $A \beta$ generation and accumulation [81-83]. Hypoxia induces $A \beta$ generation by facilitating $\beta$ - and $\gamma$-secretase cleavage of APP [84-87] and $A \beta$ accumulation by decreasing levels of enzymes responsible for $A \beta$ degradation, such as neprilysin (NEP) [88-90] and IDE [91]. Indeed, most AD patients present CAA and degenerative changes affecting arterioles and capillaries, and many show ischemic parenchymal abnormalities. These are the result of structural vascular disease and/or reduction in blood flow in critical brain areas $[92,93]$. Eliminating $A \beta$ via the vasculature is an important route for clearing brain $A \beta$, such that impairment of this process due to cerebral hypoperfusion results in $A \beta$ accumulation and the generation of vascular amyloidosis and dense-core plaques [94]. This positive feedback loop, in which vascular factors increase neurodegenerative deterioration, and vice versa, facilitates disease progression [95]. Here, we have shown that HBOT reduces hypoxia, increases $\mathrm{CBF}$ and ameliorates arterioles structure, as well as promoting $\mathrm{A} \beta$ degradation and clearance, resulting in reduced amyloid burden. These findings further show the tight interplay between vascular pathology and neurodegeneration and demonstrate the potency of HBOT in countering hypoxia-related neurological conditions, particularly AD.

In summary, we showed here that HBOT offers multifaceted neuroprotective effects on the complex pathology of Alzheimer's disease and also improves $\mathrm{CBF}$ and cognition in humans. Targeting various pathways involved in the basic pathophysiology of AD 
may offer a more potent strategy for modifying disease progression. To this point, HBOT has been demonstrated to ameliorate the pathology and improve behavior in three $\mathrm{AD}$ mouse models, namely $3 \times \mathrm{Tg}-\mathrm{AD}$, 5XFAD and APP/PS1 mice [17, 36]. Given that HBOT is considered a safe and tolerable treatment currently being used in the clinic, the increasing number of clinical trials showing that HBOT improves cognitive function in patients suffering from chronic brain damage, the pre-clinical studies elucidating mechanisms of HBOT action, and the fact that there is presently no effective intervention for $\mathrm{AD}$, HBOT should be considered as a therapeutic approach to slow the progression or even improve the pathophysiology responsible for this disease.

\section{MATERIALS AND METHODS}

\section{Mice}

Transgenic mice (Tg6799) co-overexpressing FAD mutations of human APP (the Swedish mutation, K670N/M671L; the Florida mutation, I716V; and the London mutation, V717I) and PS1 (M146L/L286V) transgenes under transcriptional control of the neuronspecific mouse Thy-1 promoter [40] were used. Hemizygous transgenic mice were crossed with C57BL/6 breeders for 10 generations. Genotyping was verified by PCR analysis of tail DNA. All animal experiments followed the "Principles of laboratory animal care" (NIH publication No-86-23 revised 1985) and were performed in accordance with animal protocols approved by the Tel Aviv University Animal Care Committee. Reporting was in accordance with ARRIVE guidelines.

\section{Hyperbaric oxygen therapy (HBOT)}

Six month-old male heterozygous 5XFAD mice and wild type (wt) C57BL/6 littermate mice were randomly assigned to two groups: HBO-treated and controls (exposed to normobaric conditions). For HBOT, animals were administered $100 \%$ oxygen at a pressure of 2 ATA in a custom-made monochamber (Supplementary Figure 3) intended for small animals for 60 minutes per day, 5 days a week for 4 weeks (i.e., 20 treatments). Before compression was initiated, the monochamber was washed with $100 \%$ oxygen for $5 \mathrm{~min}$ to enrich oxygen content. Compression and decompression were performed gradually over $5 \mathrm{~min}$. Oxygen levels inside the chamber following compression reached saturation of $\geq 96 \%$, as measured by an oxygen analyzer (320BRC model, Teledyne Analytical Instruments). Animals in the control group were placed inside the monochamber for $60 \mathrm{~min}$ at 1 ATA without additional treatment $(n=20)$.

\section{Behavioral testing}

The effects of HBOT on mouse memory and behavior were evaluated using a battery of behavioral tests. The nest building test was administered before and after 1 month of HBOT or control treatments. Tests were performed $24 \mathrm{~h}$ following the last HBOT/control treatment and was ended $48 \mathrm{~h}$ prior to sacrifice, to reduce stress.

\section{Y-maze test}

Mice were placed at the distal end of the entrance arm and allowed to explore the maze for 5 min with only the familiar arm available for exploration. After a $2 \mathrm{~min}$ delay, the mice were reintroduced into the maze with two arms (familiar and novel) available for exploration and documented for $2 \mathrm{~min}$. The ratios of time spent and the frequency of visits to the novel arm were calculated as the time or visit frequency in the novel arm divided by the sum of time or visit frequency in both the novel and familiar arms. The maze was cleaned with $40 \%$ ethanol between sessions. Arms were changed randomly between animals, yet were kept similar for each animal.

\section{Trace fear conditioning}

Mice were placed in a training chamber. After a $120 \mathrm{~s}$ baseline period, the mice received five pairings of the Conditional stimulus (CS: tone, $5 \mathrm{kHz}, 70 \mathrm{~dB}$ ) and Unconditional stimulus (US; shock $2 \mathrm{~s}, 0.7 \mathrm{~mA}$ ). The CS and US were separated by a $18 \mathrm{~s}$ empty trace interval, which increased hippocampal dependency. The inter-trial interval was set at $90 \mathrm{~s}$ [96]. The training chamber was wiped with $40 \%$ ethanol between sessions. Twenty-four hours later, the mice were again placed in the training chamber and the percentage of behavioral freezing (i.e., the absence of all but respiratory movement) during a 5 min test session was measured (contextual memory) using a FreezeFrame automated scoring system (Coulbourn Instruments).

\section{Biochemical and histological analyses}

Mice were anesthetized with ketamine and xylazine and perfused transcardially with PBS. Brains were then excised and halved and each hemisphere was further processed for either biochemical or histological analysis, as outlined below. Antibodies used in this project are listed in Supplementary Table 1.

\section{Immunochemistry}

One brain hemisphere was fixed overnight with $4 \%$ paraformaldehyde in $0.1 \mathrm{M}$ phosphate buffer ( $\mathrm{pH}$ 7.4) and 
then placed in $30 \%$ sucrose for $48 \mathrm{~h}$. Frozen coronal sections $(30 \mu \mathrm{m})$ were then cut on a sliding microtome, collected serially and stored in cryoprotectant (containing glycerin, ethylene glycol, and $0.1 \mathrm{M}$ sodium phosphate buffer, $\mathrm{pH}$ 7.4) at $-20^{\circ} \mathrm{C}$ until use. Three-four freefloating sections per animal at bregma $-1.35 \mathrm{~mm}$ and bregma -2.78 were immunostained with the following primary antibodies: biotinylated mouse anti-A $\beta$ 17-24 (4G8, 1:200; Signet Laboratories), and FITC-conjugated mouse anti-smooth muscle actin ( $\alpha$-SMA, 1:1000; SigmaAldrich). Sections were first blocked with 10-20\% normal goat serum in PBST (0.1\% triton-x-100 in PBS) for $2 \mathrm{~h}$ at room temperature, and then incubated for $24 \mathrm{~h}$ at $4^{\circ} \mathrm{C}$ with the primary antibodies (dissolved in $2 \%(\mathrm{w} / \mathrm{v})$ normal goat serum in PBST). Binding of the primary antibodies was visualized by incubating the sections for $1.5 \mathrm{~h}$ at room temperature with secondary antibodies, depending on the primary antibodies used. The sections were then mounted on slides coated with dry gelatin. $A \beta$ staining was similarly performed, except that prior to blocking, the sections were incubated with $70 \%$ formic acid for $6 \mathrm{~min}$ to increase antigen retrieval before antibody staining.

The sections were visualized using an EVOS FL microscope (Thermo Fisher; $4 \times$ and 20x magnifications) or a confocal scanning laser microscope (SP8, LEICA). Control experiments revealed no staining in sections that lacked the first antibodies and were used to determine the threshold for intensity quantification. Intensity of the immunofluorescent staining above threshold level was calculated with the Image-Pro Plus system (version 5.1, Media Cybernetics).

For SMA analysis, images were acquired from arterioles in cortical and hippocampal areas using a confocal microscope (Leica, SP8, 40x magnification). All images were acquired in a random manner blinded to subject. Vessels showing positive SMA signals and ranging in size from $10-50 \mu \mathrm{m}$ were analyzed with FIJI ImageJ software (National Institutes of Health, Bethesda, MD). A minimum of 10 and 25 arterioles were imaged for cortical and hippocampal areas per animal, respectively. For hippocampal arterioles, luminal diameter was measured as an average of the inner diameters across the section. For penetrating arterioles, diameter was assessed by determining the minimum axis of the ellipse, which is the arteriolar minor axis. Wall thickness of the medial layer was determined by measuring the external and luminal diameters and then taking half of the difference.

\section{Hypoxyprobe staining}

On the day the mice were sacrificed, half of each treatment group were injected intraperitoneally (i.p.) with $60 \mathrm{mg} / \mathrm{kg}$ of Hypoxyprobe 1 (pimonidazole hydrochloride, Hypoxyprobe, Burlington, MA) $30 \mathrm{~min}$ before tissue harvesting to detect hypoxia. Pimonidazole is distributed to all tissues, including the brain, but only forms stable adducts with thiol groups in proteins, peptides and amino acids found in hypoxic cells under conditions of partial pressure of oxygen below $10 \mathrm{~mm} \mathrm{Hg}$ at $37^{\circ} \mathrm{C}$. Brains were excised and one brain hemisphere was fixed in paraformaldehyde followed by $30 \%$ sucrose, as described above. Freefloating sections were immunostained with rabbit antipimonidazole antibodies (1:500) and visualized by Alexa Fluor 488-conjugated goat anti-rabbit secondary antibodies (1:1000). The sections were then mounted on dry-gelatin-coated slides and visualized using an EVOS FL microscope (Thermo Fisher; $4 \times$ magnification).

\section{Immunoblotting}

One brain hemisphere was snap-frozen in liquid nitrogen and stored at $-80^{\circ} \mathrm{C}$ until use. The hippocampus was excised on ice at $4^{\circ} \mathrm{C}$. Proteins were dissolved in $200 \mu \mathrm{l}$ lysis buffer containing $7.5 \mathrm{mM}$ HEPES, pH 7, $1.5 \mathrm{mM}$ EDTA, $1.5 \mathrm{mM}$ EGTA, 0.375 mM DTT, protease inhibitor cocktail (P8340, Sigma), phosphatase inhibitor cocktail (P5726, Sigma) and 2.5\% SDS (Amresco Pure, Technology Grade). Protein concentrations were determined using Bradford reagent (Bio-Rad Laboratories, Hercules, CA). Equal amounts of protein were separated on 4-20\% Bis-Tris gels (BioRad) and transferred to nitrocellulose membranes. Membranes were blocked overnight in 5\% (w/v) non-fat milk in $0.1 \%$ Tween 20 in Tris-buffered saline (TBS). After blocking, the membranes were incubated for $1 \mathrm{~h}$ at room temperature with primary antibodies specified in Supplementary Table 1.

The membranes were then washed in Tween-TBS for 20 min and incubated at room temperature with specific horseradish peroxidase-conjugated secondary antibodies as specified in Supplementary Table 1 for $60 \mathrm{~min}$. Antibody binding was revealed using enhanced chemiluminescent substrate (Pierce) and band intensity was quantified with ImageQuant TL software (Amersham). Glyceraldehyde 3-phosphate dehydrogenase (GAPDH) levels were used to verify uniform loading of the samples.

\section{A $\beta$ enzyme-linked immunosorbent assay (ELISA)}

Protein extraction was prepared by sequential ultracentrifugation of brain sub-region homogenates. Frozen tissues of hippocampus from 5XFAD mice were weighed and mechanically homogenized in four volumes of ice-cold TBS supplemented with protease inhibitors (Sigma, P8340), phosphatase inhibitors 
(Sigma, P5726) and $2 \mathrm{mM}$ EDTA. Samples were ultracentrifuged at $350,000 \mathrm{~g}$ for $30 \mathrm{~min}$ at $4^{\circ} \mathrm{C}$, and the collected supernatant was labeled as the protein TBS fraction (TBS). The pellet was dissolved in 200 $\mu 1$ of $70 \%$ formic acid supplemented with phosphatase and protease inhibitor cocktails and rotated for $2 \mathrm{~h}$ at RT. The tubes were then centrifuged at $350,000 \mathrm{~g}$ for $30 \mathrm{~min}$ at $4^{\circ} \mathrm{C}$. The supernatant was collected and 20 volumes of $1 \mathrm{M}$ Tris were added to generate protein FA fraction (FA). Levels of $A \beta 42$ and $A \beta 40$ in the hippocampus were quantified with a $\beta$-amyloid $x-42$ ELISA Kit (Biolegend, 842401) and a $\beta$-amyloid $x-40$ ELISA Kit (Biolegend, 842301), respectively. Levels of $A \beta 42$ and $A \beta 40$ are presented as $\mathrm{pg} / \mathrm{ml} A \beta$ to total protein $\mathrm{mg} / \mathrm{ml}$ protein $(\mathrm{pg} / \mathrm{mg})$.

\section{Cranial window generation and two-photon imaging}

Cranial windows were generated as previously reported [97]. Carprofen (Pfizer, $15 \mu \mathrm{g} / 25 \mathrm{~g}$ mouse) analgesia was administered sub-cutaneously prior to surgery. Mice were anesthetized with isoflurane $(5 \%$ for induction, 1-2\% thereafter), the scalp and connective tissues were excised, and the skull was covered with cyanoacrylamide. A 3-mm diameter craniotomy was performed over the barrel cortex (primary somatosensory cortex; Bregma: rostral -1.5 , lateral 3 $\mathrm{mm})$ and a custom-made $3 \mathrm{~mm}$ cover glass was placed and sealed with cyanoacrylate glue. The dry glue was covered with dental acrylic. An aluminum metal bar with two traded holes was attached to the skull. During surgery and until full recovery, the mouse was kept at $37^{\circ} \mathrm{C}$ using a heated plate. Ringer's solution $(1 \mathrm{ml})$ was administered sub-cutaneous after surgery.

For imaging, mice were anesthetized with isoflurane ( $5 \%$ for induction, $1.5 \%$ thereafter) in pure oxygen. The mice were mounted in a custom-made stage using a preattached head bar, and their temperature was maintained at $37^{\circ} \mathrm{C}$ using a heated plate. Imaging was conducted with a custom-modified two-photon laser-scanning microscope based on a Sutter MOM apparatus controlled by MPScope 2.0 software [98] using $810 \mathrm{~nm}$ excitation.

For plaque imaging, mice ( $\mathrm{n}=3-4$ per group) were injected i.p. with $10 \mathrm{mg} / \mathrm{kg}$ methoxy-X04 (TOCRIS, 4920, batch no: $2 \mathrm{~A} / 175057 ; 5 \mathrm{mg} / \mathrm{ml}$ in $10 \%$ DMSO, $45 \%$ propylene glycol, $45 \% \mathrm{PBS}, \mathrm{pH} 7.5) 24 \mathrm{~h}$ prior to each imaging session [99]. The same 3-4 fields of view, $200-400 \mu \mathrm{m}$ in depth, were imaged per animal before and after 1 month of exposure to HBOT or control treatments and plaques were sorted according to their volume. 3D reconstruction of the Methoxy-X04 plaques was done using Imaris V7.1.1 software (Imaris, RRID:SCR_007370).
For visualization of blood plasma, mice were injected with $20 \mu \mathrm{l}$ FITC (5\% w/v, i.v.; Sigma-Aldrich) via the infraorbital vein before imaging. Blood cell velocity was measured in blood vessels using arbitrary scan patterns, as previously described [100]. The same vessels were assessed prior to and following 1 month of $\mathrm{HBO} / \mathrm{control}$ treatment. Procedures for blood flow measurement and analysis have been described previously [54]. The diameter of a blood vessel and the velocity of RBCs therein can be combined to determine absolute RBC flux, which provides a complete description of blood flow in each vessel $[54,101]$ and is given by:

$$
\text { Flow }=\frac{\pi}{8} V D^{2}
$$

where $\mathrm{V}$ is the time-averaged $\mathrm{RBC}$ velocity at the center line of the vessel, and $D$ is the lumen diameter [54].

\section{Human subjects}

The study population comprised adults (5 males, 1 female) with significant memory decline aged 64 years and older, who lived independently and who were in good functional and cognitive status. The study was performed between 2016-2020 at the Shamir (AssafHarofeh) Medical Center, Israel. Patients included in the study did not have cardiac or cerebrovascular ischemia histories for the last year prior to inclusion. Exclusion criteria included previous treatment with HBOT for any reason during the last three months, any history of malignancy during the last year, any pathological cognitive decline, severe chronic renal failure (GFR < 30), uncontrolled diabetes mellitus $(\mathrm{HbA} 1 \mathrm{C}>8$, fasting glucose > 200), taking immunosuppressants, MRI contra-indications, active smoking or pulmonary diseases. Recruitment was based on social media posts and advertisements. The study protocol was approved by the Institutional Review Board of Shamir Medical Center (0172-15-ASF). Clinical trial registration: NCT02790541.

\section{HBO treatment of human subjects}

HBOT protocol was administered in a multiplace Starmed-2700 chamber (Haux, Germany). The protocol consisted of 60 daily sessions at 5 sessions per week within a three-month period. Each session included breathing $100 \%$ oxygen by mask at 2ATA for $90 \mathrm{~min}$ with 5 min air breaks every 20 min. Compression and decompression rates were $1 \mathrm{~m} / \mathrm{min}$.

\section{Cognitive assessments}

Cognitive functions were assessed using the NeuroTrax computerized testing battery, supervised by a certified 
neuropsychologist. NeuroTrax tests evaluate multiple aspects of brain cognitive function, including memory, executive function, attention, information processing speed, visual spatial, verbal and motor skills. The global cognitive domain evaluates the overall performance in all of the above categories. Cognitive domain scores were normalized for age, gender and education.

Participants completed validated alternate test forms of the NeuroTrax test battery at baseline and post-HBOT to allow for iterative administration with minimal learning effects. Test-retest reliability of the tests was found to be high in both normal and injured populations without significant learning effects, except in the verbal fluency (VF) and visual spatial (VS) domains that were not evaluated in the current study.

\section{MRI scans}

MRI scans were performed on a MAGNETOM Skyra 3T scanner, configured with 20 channel receiver head coils (Siemens Healthcare, Erlangen, Germany). Fifty T2*-weighted gradient-echo echo planar imaging (EPI) volumes were acquired. Two repetitions were performed before a bolus injection of gadoliniumDTPA (Gd-DTPA, $0.2 \mathrm{ml} / \mathrm{kg}$, administered at $5 \mathrm{ml} / \mathrm{sec}$ ), and 48 repetitions were performed after injection of GdDTPA. Sequence parameters were TR: 2,300 ms; TE: $40 \mathrm{~ms}$; flip angle: $30^{\circ}$; voxel size: $1.8 \times 1.8$, matrix: 128 $\mathrm{x}$ 128; number of slices: 25 ; and slice thickness: 3.9 $\mathrm{mm}$. Pre-processing of the perfusion MRI data was preformed using SPM software (version 12, UCL, London, UK) and included motion correction, and coregistration with MPRAGE T1 images. Individual gray matter (GM) and white matter (WM) segmentation of T1 anatomy was also performed to extract mean perfusion values. Whole-brain quantitative perfusion analysis was done as described [102, 103]. CBF values were normalized.

\section{Statistical analysis}

Statistical analyses performed are described in each figure legend. Data from nest building test and twophoton microscopy experiments were analysed by twoway ANOVA repeated measures, followed by a Fisher LSD post hoc test. Comparing analysis of all 4 treatment/genotype groups was done using two-way ANOVA followed by a Fisher LSD post hoc test. Student's $t$-test and t-test with Welch's correction were used to compare two groups of data. Data are presented as mean \pm standard error of the mean (SEM). For all analyses, statistical significance was accepted at $P<$ 0.05 and trends were defined when $P<0.10$. For MRI analysis and cognitive tests of humans, the Kolmogorov-Smirnov test, paired T-tests, and FDR corrections were used. For MRI analysis, spatial normalization to the MNI (Montreal Neurological Institute) atlas, followed by gaussian smoothing of 4 mm FWHM (full width at half maximum) was applied.

\section{Abbreviations}

AD: Alzheimer's disease; $\alpha$ - CTF: $\alpha$-secretase-cleaved Cterminal fragment; $A \beta$ : amyloid beta; APP: amyloid precursor protein; ATA: atmosphere absolute; BACE1: $\beta$ secretase-1; $\beta$-CTF: $\beta$-secretase-1 cleaved C-terminal fragment; CAA: cerebral amyloid angiopathy; $\mathrm{CBF}$ : cerebral blood flow; HBOT: hyperbaric oxygen therapy; HIF-1: hypoxia inducible factor-1; IDE: insulin-degrading enzyme; LRP1: low-density lipoprotein receptor-related protein 1; MCI: mild cognitive impairment; PSE: presenilin 1; RBCs: red blood cells; TBI: traumatic brain injury.

\section{AUTHOR CONTRIBUTIONS}

RS performed all 5XFAD mice experiments and analysis and was involved in writing the manuscript, AG was involved in performing the two-photon experiments and writing the manuscript, IG was involved in coordinating some of the experiments and writing the manuscript, ES was involved in performing and analyzing the MRI data, AH was involved in performing human-related experiments, SE was involved in designing some of the experiments, in discussions and writing the manuscript, PB coordinated the two-photon experiments, was involved in experiment design and analysis and UA was involved in coordinating the study, designing experiments, analysis and writing the manuscript.

\section{ACKNOWLEDGMENTS}

We thank Dr. Lior Bikovski for help with the behavioral tests carried out at the Myers Neuro-Behavioral Core Facility of Tel Aviv University. We also thank Drs. Robert Vasssar and Danny Frenkel for providing the 5XFAD mice and Drs. Eitan Okun and Tomer Illouz for constructive discussions. We further thank Mr. Israel Shreger help in building the HBO chamber.

\section{CONFLICTS OF INTEREST}

The authors declare that they have no conflicts of interest. AH, ES work for AVIV Scientific LTD. SE is a co-founder and shareholder at AVIV Scientific LTD.

\section{FUNDING}

This work was supported in part by the Israeli Ministry of Science, Technology and Space (grant 3-12069) and 
Israel Science Foundation (ISF grants 953/16 and 2141/20) and the Deutsche Forschungsgemeinschaft (DFG) (NA: 207/10-1) and The Aufzien Family Center for the Prevention and Treatment of Parkinson's Disease at Tel Aviv University to U.A. and by the European Research Council (ERC \#639416) and Israel Science Foundation (ISF grants 1019/15 and 1994/15) to P.B.

\section{REFERENCES}

1. Roher AE, Debbins JP, Malek-Ahmadi M, Chen K, Pipe JG, Maze S, Belden C, Maarouf CL, Thiyyagura P, Mo H, Hunter JM, Kokjohn TA, Walker DG, et al. Cerebral blood flow in Alzheimer's disease. Vasc Health Risk Manag. 2012; 8:599-611.

https://doi.org/10.2147/VHRM.S34874

PMID:23109807

2. Wolters FJ, Zonneveld HI, Hofman A, van der Lugt A, Koudstaal PJ, Vernooij MW, Ikram MA, and Heart-Brain Connection Collaborative Research Group. Cerebral Perfusion and the Risk of Dementia: A PopulationBased Study. Circulation. 2017; 136:719-28. https://doi.org/10.1161/CIRCULATIONAHA.117.02744 8 PMID:28588075

3. Akoudad S, Wolters FJ, Viswanathan A, de Bruijn RF, van der Lugt A, Hofman A, Koudstaal PJ, Ikram MA, Vernooij MW. Association of Cerebral Microbleeds With Cognitive Decline and Dementia. JAMA Neurol. 2016; 73:934-43.

https://doi.org/10.1001/jamaneurol.2016.1017 PMID:27271785

4. Santos CY, Snyder PJ, Wu WC, Zhang M, Echeverria A, Alber J. Pathophysiologic relationship between Alzheimer's disease, cerebrovascular disease, and cardiovascular risk: A review and synthesis. Alzheimers Dement (Amst). 2017; 7:69-87.

https://doi.org/10.1016/i.dadm.2017.01.005

PMID:28275702

5. Vinters HV. Cerebral amyloid angiopathy. A critical review. Stroke. 1987; 18:311-24.

https://doi.org/10.1161/01.str.18.2.311

PMID:3551211

6. Jellinger KA. Alzheimer disease and cerebrovascular pathology: an update. J Neural Transm (Vienna). 2002; 109:813-36.

https://doi.org/10.1007/s007020200068

PMID: 12111471

7. Iturria-Medina $\mathrm{Y}$, Sotero RC, Toussaint PJ, MateosPérez JM, Evans AC, and Alzheimer's Disease Neuroimaging Initiative. Early role of vascular dysregulation on late-onset Alzheimer's disease based on multifactorial data-driven analysis. Nat Commun.
2016; 7:11934.

https://doi.org/10.1038/ncomms11934

PMID:27327500

8. de Eulate RG, Goñi I, Galiano A, Vidorreta M, Recio M, Riverol M, Zubieta JL, Fernández-Seara MA. Reduced Cerebral Blood Flow in Mild Cognitive Impairment Assessed Using Phase-Contrast MRI. J Alzheimers Dis. 2017; 58:585-95. https://doi.org/10.3233/JAD-161222 PMID:28453476

9. Ruitenberg A, den Heijer T, Bakker SL, van Swieten JC, Koudstaal PJ, Hofman A, Breteler MM. Cerebral hypoperfusion and clinical onset of dementia: the Rotterdam Study. Ann Neurol. 2005; 57:789-94. https://doi.org/10.1002/ana.20493 PMID:15929050

10. Benedictus MR, Leeuwis AE, Binnewijzend MA, Kuijer JP, Scheltens $P$, Barkhof $F$, van der Flier WM, Prins ND. Lower cerebral blood flow is associated with faster cognitive decline in Alzheimer's disease. Eur Radiol. 2017; 27:1169-75.

https://doi.org/10.1007/s00330-016-4450-z

PMID:27334014

11. Bradley KM, O'Sullivan VT, Soper ND, Nagy Z, King EM, Smith AD, Shepstone BJ. Cerebral perfusion SPET correlated with Braak pathological stage in Alzheimer's disease. Brain. 2002; 125:1772-81.

https://doi.org/10.1093/brain/awf185 PMID:12135968

12. Binnewijzend $M A$, Schoonheim MM, Sanz-Arigita $E$, Wink AM, van der Flier WM, Tolboom N, Adriaanse SM, Damoiseaux JS, Scheltens P, van Berckel BN, Barkhof F. Resting-state fMRI changes in Alzheimer's disease and mild cognitive impairment. Neurobiol Aging. 2012; 33:2018-28.

https://doi.org/10.1016/j.neurobiolaging.2011.07.003 PMID:21862179

13. Niwa K, Kazama K, Younkin SG, Carlson GA, ladecola C. Alterations in cerebral blood flow and glucose utilization in mice overexpressing the amyloid precursor protein. Neurobiol Dis. 2002; 9:61-68.

https://doi.org/10.1006/nbdi.2001.0460 PMID:11848685

14. Li H, Guo Q, Inoue T, Polito VA, Tabuchi K, Hammer RE, Pautler RG, Taffet GE, Zheng $H$. Vascular and parenchymal amyloid pathology in an Alzheimer disease knock-in mouse model: interplay with cerebral blood flow. Mol Neurodegener. 2014; 9:28.

https://doi.org/10.1186/1750-1326-9-28 PMID:25108425

15. Cruz Hernández JC, Bracko O, Kersbergen CJ, Muse V, Haft-Javaherian M, Berg M, Park L, Vinarcsik LK, Ivasyk I, Rivera DA, Kang Y, Cortes-Canteli M, Peyrounette M, et al. Neutrophil adhesion in brain capillaries reduces cortical blood flow and impairs memory function in Alzheimer's disease mouse models. Nat Neurosci. 
2019; 22:413-20.

https://doi.org/10.1038/s41593-018-0329-4

PMID: 30742116

16. Lin AJ, Liu G, Castello NA, Yeh JJ, Rahimian R, Lee G, Tsay V, Durkin AJ, Choi B, LaFerla FM, Chen Z, Green $\mathrm{KN}$, Tromberg BJ. Optical imaging in an Alzheimer's mouse model reveals amyloid- $\beta$-dependent vascular impairment. Neurophotonics. 2014; 1:011005.

https://doi.org/10.1117/1.NPh.1.1.011005

PMID:25133200

17. Shapira R, Solomon B, Efrati S, Frenkel D, Ashery U. Hyperbaric oxygen therapy ameliorates pathophysiology of 3xTg-AD mouse model by attenuating neuroinflammation. Neurobiol Aging. 2018; 62:105-19.

https://doi.org/10.1016/j.neurobiolaging.2017.10.007 PMID:29141186

18. Paris D, Patel N, DelleDonne A, Quadros A, Smeed R, Mullan $M$. Impaired angiogenesis in a transgenic mouse model of cerebral amyloidosis. Neurosci Lett. 2004; 366:80-85.

https://doi.org/10.1016/j.neulet.2004.05.017 PMID:15265595

19. Ielacqua $G D$, Schlegel $F$, Füchtemeier $M$, Xandry J, Rudin M, Klohs J. Magnetic Resonance Q Mapping Reveals a Decrease in Microvessel Density in the $\operatorname{arcA} \beta$ Mouse Model of Cerebral Amyloidosis. Front Aging Neurosci. 2016; 7:241.

https://doi.org/10.3389/fnagi.2015.00241

PMID:26834622

20. Niwa K, Porter VA, Kazama K, Cornfield D, Carlson GA, ladecola C. A beta-peptides enhance vasoconstriction in cerebral circulation. Am J Physiol Heart Circ Physiol. 2001; 281:H2417-24.

https://doi.org/10.1152/ajpheart.2001.281.6.H2417 PMID:11709407

21. Luo F, Seifert TR, Edalji R, Loebbert RW, Hradil VP, Harlan J, Schmidt M, Nimmrich V, Cox BF, Fox GB. Noninvasive characterization of beta-amyloid(1-40) vasoactivity by functional magnetic resonance imaging in mice. Neuroscience. 2008; 155:263-69.

https://doi.org/10.1016/j.neuroscience.2008.04.021 PMID:18534764

22. Lourenço CF, Ledo A, Barbosa RM, Laranjinha J. Neurovascular uncoupling in the triple transgenic model of Alzheimer's disease: Impaired cerebral blood flow response to neuronal-derived nitric oxide signaling. Exp Neurol. 2017; 291:36-43.

https://doi.org/10.1016/i.expneurol.2017.01.013 PMID:28161255

23. Kimbrough IF, Robel S, Roberson ED, Sontheimer $\mathrm{H}$. Vascular amyloidosis impairs the gliovascular unit in a mouse model of Alzheimer's disease. Brain. 2015;
138:3716-33.

https://doi.org/10.1093/brain/awv327

PMID:26598495

24. Yata $\mathrm{K}$, Tomimoto $\mathrm{H}$. Chronic cerebral hypoperfusion and dementia. Neurol Clin Neurosci. 2014; 2:129-34. https://doi.org/10.1111/ncn3.124

25. Thom SR. Hyperbaric oxygen: its mechanisms and efficacy. Plast Reconstr Surg. 2011 (Suppl 1); 127:131S-41S.

https://doi.org/10.1097/PRS.0b013e3181fbe2bf PMID:21200283

26. Matera DV, Smith B, Lam B. Revisiting the expanded use of hyperbaric oxygen therapy for treatment of resistant migraines. Med Gas Res. 2019; 9:238-40.

https://doi.org/10.4103/2045-9912.273963 PMID:31898611

27. Price M. Hyperbaric Oxygen Therapy: The Difference Between FDA Approval and FDA Non-Approval. 2021. https://www.rehabmart.com/post/hyperbaric-oxygentherapy-the-difference-between-fda-approval-and-fdanonapproval

28. Zhai WW, Sun L, Yu ZQ, Chen G. Hyperbaric oxygen therapy in experimental and clinical stroke. Med Gas Res. 2016; 6:111-18. https://doi.org/10.4103/2045-9912.184721 PMID:27867477

29. Pekovic S, Dacic S, Krstic D, Jeremic R, Djelic M, Brkic P. Hyperbaric Oxygen Therapy in Traumatic Brain Injury: Cellular and Molecular Mechanisms. In: Drenjančević I, editor. Hyperbaric Oxygen Treatment in Research and Clinical Practice. Rijeka: IntechOpen. 2018.

30. Gill AL, Bell CN. Hyperbaric oxygen: its uses, mechanisms of action and outcomes. QJM. 2004; 97:385-95.

https://doi.org/10.1093/qjmed/hch074 PMID:15208426

31. Hadanny A, Abbott S, Suzin G, Bechor Y, Efrati S. Effect of hyperbaric oxygen therapy on chronic neurocognitive deficits of post-traumatic brain injury patients: retrospective analysis. BMJ Open. 2018; 8:e023387.

https://doi.org/10.1136/bmjopen-2018-023387 PMID:30269074

32. Shandley S, Wolf EG, Schubert-Kappan CM, Baugh LM, Richards MF, Prye J, Arizpe HM, Kalns J. Increased circulating stem cells and better cognitive performance in traumatic brain injury subjects following hyperbaric oxygen therapy. Undersea Hyperb Med. 2017; 44:257-69. https://doi.org/10.22462/5.6.2017.6 PMID:28779582

33. Tal S, Hadanny A, Sasson E, Suzin G, Efrati S. Hyperbaric 
Oxygen Therapy Can Induce Angiogenesis and Regeneration of Nerve Fibers in Traumatic Brain Injury Patients. Front Hum Neurosci. 2017; 11:508.

https://doi.org/10.3389/fnhum.2017.00508

PMID:29097988

34. Chen L, Li F, Gu D. Hyperbaric oxygen therapy for cerebral blood flow and electroencephalogram in patients with acute cerebral infarction: Choice for therapeutic occasion. Neural Regen Res. 2007; 2:171-74.

https://doi.org/10.1016/S1673-5374(07)60038-3

35. Rosario ER, Kaplan SE, Khonsari S, Vazquez G, Solanki $\mathrm{N}$, Lane M, Brownell H, Rosenberg SS. The Effect of Hyperbaric Oxygen Therapy on Functional Impairments Caused by Ischemic Stroke. Neurol Res Int. 2018; 2018:3172679.

https://doi.org/10.1155/2018/3172679

PMID:30402285

36. Choi J, Kwon HJ, Lee JE, Lee Y, Seoh JY, Han PL. Hyperoxygenation revitalizes Alzheimer's disease pathology through the upregulation of neurotrophic factors. Aging Cell. 2019; 18:e12888. https://doi.org/10.1111/acel.12888 PMID:30746828

37. Harch PG, Fogarty EF. Hyperbaric oxygen therapy for Alzheimer's dementia with positron emission tomography imaging: a case report. Med Gas Res. 2019; 8:181-84.

https://doi.org/10.4103/2045-9912.248271 PMID:30713673

38. Xu Y, Wang Q, Qu Z, Yang J, Zhang X, Zhao Y. Protective Effect of Hyperbaric Oxygen Therapy on Cognitive Function in Patients with Vascular Dementia. Cell Transplant. 2019; 28:1071-75. https://doi.org/10.1177/0963689719853540 PMID: $\underline{31134827}$

39. Chen J, Zhang F, Zhao L, Cheng C, Zhong R, Dong C, Le W. Hyperbaric oxygen ameliorates cognitive impairment in patients with Alzheimer's disease and amnestic mild cognitive impairment. Alzheimers Dement (N Y). 2020; 6:e12030. https://doi.org/10.1002/trc2.12030 PMID: $\underline{32548235}$

40. Oakley H, Cole SL, Logan S, Maus E, Shao P, Craft J, Guillozet-Bongaarts A, Ohno M, Disterhoft J, Van Eldik L, Berry R, Vassar R. Intraneuronal beta-amyloid aggregates, neurodegeneration, and neuron loss in transgenic mice with five familial Alzheimer's disease mutations: potential factors in amyloid plaque formation. J Neurosci. 2006; 26:10129-40. https://doi.org/10.1523/JNEUROSCl.1202-06.2006 PMID:17021169

41. Giannoni P, Arango-Lievano M, Neves ID, Rousset MC, Baranger K, Rivera S, Jeanneteau F, Claeysen S, Marchi
N. Cerebrovascular pathology during the progression of experimental Alzheimer's disease. Neurobiol Dis. 2016; 88:107-17.

https://doi.org/10.1016/i.nbd.2016.01.001

PMID:26774030

42. Kook SY, Seok Hong $H$, Moon M, Mook-Jung I. Disruption of blood-brain barrier in Alzheimer disease pathogenesis. Tissue Barriers. 2013; 1:e23993. https://doi.org/10.4161/tisb.23993 PMID:24665385

43. Holtmaat A, Bonhoeffer T, Chow DK, Chuckowree J, De Paola V, Hofer SB, Hübener M, Keck T, Knott G, Lee WC, Mostany R, Mrsic-Flogel TD, Nedivi E, et al. Longterm, high-resolution imaging in the mouse neocortex through a chronic cranial window. Nat Protoc. 2009; 4:1128-44. https://doi.org/10.1038/nprot.2009.89 PMID:19617885

44. Yan P, Bero AW, Cirrito JR, Xiao Q, Hu X, Wang Y, Gonzales E, Holtzman DM, Lee JM. Characterizing the appearance and growth of amyloid plaques in APP/PS1 mice. J Neurosci. 2009; 29:10706-14. https://doi.org/10.1523/JNEUROSCl.2637-09.2009 PMID:19710322

45. Burgold $S$, Bittner $T$, Dorostkar MM, Kieser $D$, Fuhrmann M, Mitteregger G, Kretzschmar H, Schmidt $\mathrm{B}$, Herms J. In vivo multiphoton imaging reveals gradual growth of newborn amyloid plaques over weeks. Acta Neuropathol. 2011; 121:327-35. https://doi.org/10.1007/s00401-010-0787-6 PMID:21136067

46. Thinakaran G, Koo EH. Amyloid precursor protein trafficking, processing, and function. J Biol Chem. 2008; 283:29615-19. https://doi.org/10.1074/jbc.R800019200 PMID:18650430

47. Heneka MT, Kummer MP, Stutz A, Delekate $A$, Schwartz S, Vieira-Saecker A, Griep A, Axt D, Remus A, Tzeng TC, Gelpi E, Halle A, Korte M, et al. NLRP3 is activated in Alzheimer's disease and contributes to pathology in APP/PS1 mice. Nature. 2013; 493:674-78. https://doi.org/10.1038/nature11729 PMID:23254930

48. Miners JS, Barua N, Kehoe PG, Gill S, Love S. A $\beta$ degrading enzymes: potential for treatment of Alzheimer disease. J Neuropathol Exp Neurol. 2011; 70:944-59.

https://doi.org/10.1097/NEN.0b013e3182345e46 PMID:22002425

49. Ramanathan A, Nelson AR, Sagare AP, Zlokovic BV. Impaired vascular-mediated clearance of brain amyloid beta in Alzheimer's disease: the role, regulation and restoration of LRP1. Front Aging Neurosci. 2015; 7:136. https://doi.org/10.3389/fnagi.2015.00136 
PMID: 26236233

50. Kanekiyo T, Liu CC, Shinohara M, Li J, Bu G. LRP1 in brain vascular smooth muscle cells mediates local clearance of Alzheimer's amyloid- $\beta$. J Neurosci. 2012; 32:16458-65.

https://doi.org/10.1523/JNEUROSCl.3987-12.2012 PMID:23152628

51. Kanekiyo T, Cirrito JR, Liu CC, Shinohara M, Li J, Schuler DR, Shinohara M, Holtzman DM, Bu G. Neuronal clearance of amyloid- $\beta$ by endocytic receptor LRP1. J Neurosci. 2013; 33:19276-83.

https://doi.org/10.1523/JNEUROSCI.3487-13.2013 PMID:24305823

52. Liu CC, Hu J, Zhao N, Wang J, Wang N, Cirrito JR, Kanekiyo T, Holtzman DM, Bu G. Astrocytic LRP1 Mediates Brain $A \beta$ Clearance and Impacts Amyloid Deposition. J Neurosci. 2017; 37:4023-31. https://doi.org/10.1523/JNEUROSCI.3442-16.2017 PMID:28275161

53. Dirnagl U, Kaplan B, Jacewicz M, Pulsinelli W. Continuous measurement of cerebral cortical blood flow by laser-Doppler flowmetry in a rat stroke model. J Cereb Blood Flow Metab. 1989; 9:589-96. https://doi.org/10.1038/jcbfm.1989.84 PMID:2674168

54. Shih AY, Driscoll JD, Drew PJ, Nishimura N, Schaffer CB, Kleinfeld D. Two-photon microscopy as a tool to study blood flow and neurovascular coupling in the rodent brain. J Cereb Blood Flow Metab. 2012; 32:1277-309. https://doi.org/10.1038/jcbfm.2011.196 PMID:22293983

55. Stopa EG, Butala P, Salloway S, Johanson CE, Gonzalez L, Tavares R, Hovanesian V, Hulette CM, Vitek MP, Cohen RA. Cerebral cortical arteriolar angiopathy, vascular beta-amyloid, smooth muscle actin, Braak stage, and APOE genotype. Stroke. 2008; 39:814-21. https://doi.org/10.1161/STROKEAHA.107.493429 PMID:18258839

56. Merlini M, Wanner D, Nitsch RM. Tau pathologydependent remodelling of cerebral arteries precedes Alzheimer's disease-related microvascular cerebral amyloid angiopathy. Acta Neuropathol. 2016; 131:737-52.

https://doi.org/10.1007/s00401-016-1560-2 PMID:26988843

57. Ogunshola OO, Antoniou X. Contribution of hypoxia to Alzheimer's disease: is HIF-1alpha a mediator of neurodegeneration? Cell Mol Life Sci. 2009; 66:3555-63.

https://doi.org/10.1007/s00018-009-0141-0 PMID:19763399

58. Huerta PT, Sun LD, Wilson MA, Tonegawa S. Formation of temporal memory requires NMDA receptors within
CA1 pyramidal neurons. Neuron. 2000; 25:473-80. https://doi.org/10.1016/s0896-6273(00)80909-5 PMID:10719900

59. Misane I, Tovote P, Meyer M, Spiess J, Ogren SO, Stiedl O. Time-dependent involvement of the dorsal hippocampus in trace fear conditioning in mice. Hippocampus. 2005; 15:418-26. https://doi.org/10.1002/hipo.20067 PMID:15669102

60. Fanselow MS. Contextual fear, gestalt memories, and the hippocampus. Behav Brain Res. 2000; 110:73-81. https://doi.org/10.1016/s0166-4328(99)00186-2 PMID:10802305

61. Anderson RM, Hadjichrysanthou C, Evans S, Wong MM. Why do so many clinical trials of therapies for Alzheimer's disease fail? Lancet. 2017; 390:2327-29. https://doi.org/10.1016/S0140-6736(17)32399-1 PMID:29185425

62. Huang LK, Chao SP, Hu CJ. Clinical trials of new drugs for Alzheimer disease. J Biomed Sci. 2020; 27:18. https://doi.org/10.1186/s12929-019-0609-7 PMID:31906949

63. Long JM, Holtzman DM. Alzheimer Disease: An Update on Pathobiology and Treatment Strategies. Cell. 2019; 179:312-39.

https://doi.org/10.1016/i.cell.2019.09.001 PMID:31564456

64. Zonneveld HI, Loehrer EA, Hofman A, Niessen WJ, van der Lugt A, Krestin GP, Ikram MA, Vernooij MW. The bidirectional association between reduced cerebral blood flow and brain atrophy in the general population. J Cereb Blood Flow Metab. 2015; 35:1882-87.

https://doi.org/10.1038/jcbfm.2015.157 PMID:26154865

65. de la Torre JC, Mussivand T. Can disturbed brain microcirculation cause Alzheimer's disease? Neurol Res. 1993; 15:146-53.

https://doi.org/10.1080/01616412.1993.11740127 PMID:103579

66. de la Torre JC. Cerebral hemodynamics and vascular risk factors: setting the stage for Alzheimer's disease. J Alzheimers Dis. 2012; 32:553-67. https://doi.org/10.3233/JAD-2012-120793 PMID:22842871

67. Vadas D, Kalichman L, Hadanny A, Efrati S. Hyperbaric Oxygen Environment Can Enhance Brain Activity and Multitasking Performance. Front Integr Neurosci. 2017; 11:25. https://doi.org/10.3389/fnint.2017.00025 PMID:29021747

68. Hadanny A, Daniel-Kotovsky M, Suzin G, Boussi-Gross R, Catalogna M, Dagan K, Hachmo Y, Abu Hamed R, Sasson E, Fishlev G, Lang E, Polak N, Doenyas K, et al. 
Cognitive enhancement of healthy older adults using hyperbaric oxygen: a randomized controlled trial. Aging (Albany NY). 2020; 12:13740-61.

https://doi.org/10.18632/aging.103571

PMID:32589613

69. Harch PG, Fogarty EF, Staab PK, Van Meter K. Low pressure hyperbaric oxygen therapy and SPECT brain imaging in the treatment of blast-induced chronic traumatic brain injury (post-concussion syndrome) and post traumatic stress disorder: a case report. Cases J. 2009; 2:6538.

https://doi.org/10.4076/1757-1626-2-6538 PMID:19829822

70. Golden ZL, Neubauer R, Golden CJ, Greene L, Marsh J, Mleko A. Improvement in cerebral metabolism in chronic brain injury after hyperbaric oxygen therapy. Int J Neurosci. 2002; 112:119-31.

https://doi.org/10.1080/00207450212027

PMID:12325401

71. Wang $H$, Wang $Y$, Hong $X$, Li S, Wang Y. Quantitative Proteomics Reveals the Mechanism of Oxygen Treatment on Lenses of Alzheimer's Disease Model Mice. J Alzheimers Dis. 2016; 54:275-86.

https://doi.org/10.3233/JAD-160263

PMID:27567828

72. Shabir O, Sharp P, Rebollar MA, Boorman L, Howarth C, Wharton SB, Francis SE, Berwick J. Enhanced Cerebral Blood Volume under Normobaric Hyperoxia in the J20hAPP Mouse Model of Alzheimer's Disease. Sci Rep. 2020; 10:7518.

https://doi.org/10.1038/s41598-020-64334-4

PMID:32371859

73. You Q, Li L, Xiong SQ, Yan YF, Li D, Yan NN, Chen HP, Liu YP. Meta-Analysis on the Efficacy and Safety of Hyperbaric Oxygen as Adjunctive Therapy for Vascular Dementia. Front Aging Neurosci. 2019; 11:86.

https://doi.org/10.3389/fnagi.2019.00086

PMID:31057392

74. Dong J, Revilla-Sanchez R, Moss S, Haydon PG. Multiphoton in vivo imaging of amyloid in animal models of Alzheimer's disease. Neuropharmacology. 2010; 59:268-75.

https://doi.org/10.1016/i.neuropharm.2010.04.007 PMID:20398680

75. HefendehI JK, Wegenast-Braun BM, Liebig C, Eicke D, Milford D, Calhoun ME, Kohsaka S, Eichner M, Jucker $M$. Long-term in vivo imaging of $\beta$-amyloid plaque appearance and growth in a mouse model of cerebral ß-amyloidosis. J Neurosci. 2011; 31:624-29. https://doi.org/10.1523/JNEUROSCI.5147-10.2011 PMID:21228171

76. Li H, Wu J, Zhu L, Sha L, Yang S, Wei J, Ji L, Tang X, Mao
K, Cao L, Wei N, Xie W, Yang Z. Insulin degrading enzyme contributes to the pathology in a mixed model of Type 2 diabetes and Alzheimer's disease: possible mechanisms of IDE in T2D and AD. Biosci Rep. 2018; 38:BSR20170862.

https://doi.org/10.1042/BSR20170862

PMID:29222348

77. Lu XY, Huang S, Chen QB, Zhang D, Li W, Ao R, Leung FC, Zhang Z, Huang J, Tang $Y$, Zhang SJ. Metformin Ameliorates A $\beta$ Pathology by Insulin-Degrading Enzyme in a Transgenic Mouse Model of Alzheimer's Disease. Oxid Med Cell Longev. 2020; 2020:2315106. https://doi.org/10.1155/2020/2315106 PMID:32377293

78. Shinohara M, Sato N, Kurinami H, Takeuchi D, Takeda S, Shimamura M, Yamashita T, Uchiyama Y, Rakugi $H$, Morishita R. Reduction of brain beta-amyloid (Abeta) by fluvastatin, a hydroxymethylglutaryl-CoA reductase inhibitor, through increase in degradation of amyloid precursor protein C-terminal fragments (APP-CTFs) and Abeta clearance. J Biol Chem. 2010; 285:22091-102.

https://doi.org/10.1074/jbc.M110.102277 PMID:20472556

79. Daria A, Colombo A, Llovera G, Hampel H, Willem M, Liesz A, Haass C, Tahirovic S. Young microglia restore amyloid plaque clearance of aged microglia. EMBO J. 2017; 36:583-603.

https://doi.org/10.15252/embj.201694591 PMID:28007893

80. Martorell AJ, Paulson $A L$, Suk $H J$, Abdurrob $F$, Drummond GT, Guan W, Young JZ, Kim DN, Kritskiy O, Barker SJ, Mangena V, Prince SM, Brown EN, et al. Multi-sensory Gamma Stimulation Ameliorates Alzheimer's-Associated Pathology and Improves Cognition. Cell. 2019; 177:256-71.e22. https://doi.org/10.1016/i.cell.2019.02.014 PMID: $\underline{30879788}$

81. Dickstein DL, Walsh J, Brautigam H, Stockton SD Jr, Gandy S, Hof PR. Role of vascular risk factors and vascular dysfunction in Alzheimer's disease. Mt Sinai J Med. 2010; 77:82-102.

https://doi.org/10.1002/msj.20155 PMID:20101718

82. Beach TG, Wilson JR, Sue LI, Newell A, Poston M, Cisneros R, Pandya Y, Esh C, Connor DJ, Sabbagh M, Walker DG, Roher AE. Circle of Willis atherosclerosis: association with Alzheimer's disease, neuritic plaques and neurofibrillary tangles. Acta Neuropathol. 2007; 113:13-21.

https://doi.org/10.1007/s00401-006-0136-y PMID:17021755

83. Bannai T, Mano T, Chen X, Ohtomo G, Ohtomo R, Tsuchida T, Koshi-Mano K, Hashimoto T, Okazawa H, Iwatsubo T, Tsuji S, Toda T, Iwata A. Chronic cerebral 
hypoperfusion shifts the equilibrium of amyloid $\beta$ oligomers to aggregation-prone species with higher molecular weight. Sci Rep. 2019; 9:2827.

https://doi.org/10.1038/s41598-019-39494-7 PMID:30808940

84. Bazan NG, Lukiw WJ. Cyclooxygenase-2 and presenilin1 gene expression induced by interleukin-1beta and amyloid beta 42 peptide is potentiated by hypoxia in primary human neural cells. J Biol Chem. 2002; 277:30359-67.

https://doi.org/10.1074/ibc.M203201200

PMID: $\underline{12050157}$

85. Li L, Zhang X, Yang D, Luo G, Chen S, Le W. Hypoxia increases Abeta generation by altering beta- and gamma-cleavage of APP. Neurobiol Aging. 2009; 30:1091-98.

https://doi.org/10.1016/i.neurobiolaging.2007.10.011 PMID:18063223

86. Liu H, Qiu H, Yang J, Ni J, Le W. Chronic hypoxia facilitates Alzheimer's disease through demethylation of $\gamma$-secretase by downregulating DNA methyltransferase 3b. Alzheimers Dement. 2016; 12:130-43.

https://doi.org/10.1016/i.jalz.2015.05.019

PMID:26121910

87. Zhang $X$, Zhou K, Wang R, Cui J, Lipton SA, Liao FF, Xu $H$, Zhang YW. Hypoxia-inducible factor 1alpha (HIF1alpha)-mediated hypoxia increases BACE1 expression and beta-amyloid generation. J Biol Chem. 2007; 282:10873-80.

https://doi.org/10.1074/ibc.M608856200 PMID:17303576

88. Nalivaeva NN, Belyaev ND, Lewis DI, Pickles AR, Makova NZ, Bagrova DI, Dubrovskaya NM, Plesneva SA, Zhuravin IA, Turner AJ. Effect of sodium valproate administration on brain neprilysin expression and memory in rats. J Mol Neurosci. 2012; 46:569-77.

https://doi.org/10.1007/s12031-011-9644-x PMID:21932040

89. Fisk L, Nalivaeva NN, Boyle JP, Peers CS, Turner AJ. Effects of hypoxia and oxidative stress on expression of neprilysin in human neuroblastoma cells and rat cortical neurones and astrocytes. Neurochem Res. 2007; 32:1741-48.

https://doi.org/10.1007/s11064-007-9349-2 PMID:17486446

90. Wang Z, Zhang XJ, Li T, Li J, Tang Y, Le W. Valproic acid reduces neuritic plaque formation and improves learning deficits in APP(Swe) /PS1(A246E) transgenic mice via preventing the prenatal hypoxia-induced down-regulation of neprilysin. CNS Neurosci Ther. 2014; 20:209-17.

https://doi.org/10.1111/cns.12186
PMID: 24289518

91. de Dios C, Bartolessis I, Roca-Agujetas V, BarberoCamps E, Mari M, Morales A, Colell A. Oxidative inactivation of amyloid beta-degrading proteases by cholesterol-enhanced mitochondrial stress. Redox Biol. 2019; 26:101283.

https://doi.org/10.1016/j.redox.2019.101283 PMID: $\underline{31376793}$

92. Thomas T, Miners S, Love S. Post-mortem assessment of hypoperfusion of cerebral cortex in Alzheimer's disease and vascular dementia. Brain. 2015; 138:1059-69.

https://doi.org/10.1093/brain/awv025 PMID:25688080

93. Toledo JB, Arnold SE, Raible K, Brettschneider J, Xie SX, Grossman M, Monsell SE, Kukull WA, Trojanowski JQ. Contribution of cerebrovascular disease in autopsy confirmed neurodegenerative disease cases in the National Alzheimer's Coordinating Centre. Brain. 2013; 136:2697-706.

https://doi.org/10.1093/brain/awt188 PMID:23842566

94. Mazza M, Marano G, Traversi G, Bria P, Mazza S. Primary cerebral blood flow deficiency and Alzheimer's disease: shadows and lights. J Alzheimers Dis. 2011; 23:375-89.

https://doi.org/10.3233/JAD-2010-090700

PMID:21098977

95. Rius-Pérez $S$, Tormos AM, Pérez $S$, Taléns-Visconti R. Vascular pathology: Cause or effect in Alzheimer disease? Neurologia (Engl Ed). 2018; 33:112-20. https://doi.org/10.1016/i.nrl.2015.07.010 PMID:26385017

96. Moore MD, Cushman J, Chandra D, Homanics GE, Olsen RW, Fanselow MS. Trace and contextual fear conditioning is enhanced in mice lacking the alpha4 subunit of the GABA(A) receptor. Neurobiol Learn Mem. 2010; 93:383-87.

https://doi.org/10.1016/i.nlm.2009.12.004 PMID:20018248

97. Gdalyahu A, Tring E, Polack PO, Gruver R, Golshani P, Fanselow MS, Silva AJ, Trachtenberg JT. Associative fear learning enhances sparse network coding in primary sensory cortex. Neuron. 2012; 75:121-32.

https://doi.org/10.1016/i.neuron.2012.04.035 PMID:22794266

98. Nguyen QT, Dolnick EM, Driscoll J, Kleinfeld D. MPScope 2.0: A computer system for two-photon laser scanning microscopy with concurrent plasmamediated ablation and electrophysiology. In: Frostig $\mathrm{RD}$, editor. In vivo Optical Imaging of Brain Function. 2nd ed. Boca Raton (FL): CRC Press/Taylor \& Francis; 2009; 117-42. PMID: $\underline{26844327}$ 
99. Klunk WE, Bacskai BJ, Mathis CA, Kajdasz ST, McLellan ME, Frosch MP, Debnath ML, Holt DP, Wang Y, Hyman BT. Imaging Abeta plaques in living transgenic mice with multiphoton microscopy and methoxy-X04, a systemically administered Congo red derivative. J Neuropathol Exp Neurol. 2002; 61:797-805.

https://doi.org/10.1093/inen/61.9.797

PMID:12230326

100. Driscoll JD, Shih AY, Drew PJ, Cauwenberghs G, Kleinfeld D. Two-photon imaging of blood flow in the rat cortex. Cold Spring Harb Protoc. 2013; 2013:759-67. https://doi.org/10.1101/pdb.prot076513 PMID:23906919

101. Shih AY, Friedman B, Drew PJ, Tsai PS, Lyden PD, Kleinfeld D. Active dilation of penetrating arterioles restores red blood cell flux to penumbral neocortex after focal stroke. J Cereb Blood Flow Metab. 2009; 29:738-51.

https://doi.org/10.1038/jcbfm.2008.166

PMID:19174826
102. Ostergaard L, Weisskoff RM, Chesler DA, Gyldensted C, Rosen BR. High resolution measurement of cerebral blood flow using intravascular tracer bolus passages. Part I: Mathematical approach and statistical analysis. Magn Reson Med. 1996; 36:715-25. https://doi.org/10.1002/mrm.1910360510 PMID:8916022

103. Ostergaard L, Sorensen AG, Kwong KK, Weisskoff RM, Gyldensted C, Rosen BR. High resolution measurement of cerebral blood flow using intravascular tracer bolus passages. Part II: Experimental comparison and preliminary results. Magn Reson Med. 1996; 36:726-36. https://doi.org/10.1002/mrm.1910360511 PMID: 8916023 


\section{SUPPLEMENTARY MATERIALS}

\section{Supplementary Methods}

\section{Quantifying plaque-associated microglia}

For analysis of plaque-associated microglia, costaining of Iba1 and amyloid plaques was conducted using biotinylated mouse anti-A $\beta$ 17-24 (4G8, 1:200; Signet Laboratories) and rabbit anti-Iba1 antibodies (1:700, Wako) (as detailed in 'Immunochemistry' section) and the number of microglia associated to plaque and the volumes of plaque $\left(\mu \mathrm{m}^{3}\right)$ in the CA1 area were measured with FIJI Image $J$ software (National Institutes of Health, Bethesda, MD). Then, microglia number was normalized per plaque volume.

\section{Behavioral testing}

The effects of HBOT on memory and behavior in mice were evaluated using a battery of behavioral tests. Tests were performed $24 \mathrm{hr}$ following the last HBO / control treatment and finished $48 \mathrm{~h}$ prior to sacrifice to reduce stress.

\section{Nest building test}

The ability of 5XFAD and wt mice to build a nest over night was assessed prior to and following 1 month of HBOT or control normobaric conditions. Mice were placed individually into cages with bedding covering the floor to a depth of $0.5 \mathrm{~cm}$ and 2 round pressed cotton batting ('nestlets') about one hour before the dark phase, and the results were assessed the next morning. Results were assessed by scoring nest construction according to the established system of Deacon $[1,2]$ with a 5-point scale and measuring nests height.

\section{Open field test}

Animals were placed in the center of an open field $(40 \mathrm{~cm}$ $\times 40 \mathrm{~cm} \times 30 \mathrm{~cm}$ ) and exploration was assessed for $5 \mathrm{~min}$. Cages were cleaned with ethanol following each session.

\section{Antibodies list}

All antibodies used are detailed below in Supplementary Table 1.

\section{REFERENCES}

1. Deacon R. Assessing burrowing, nest construction, and hoarding in mice. J Vis Exp. 2012; e2607. https://doi.org/10.3791/2607 PMID:22258546

2. Deacon RM. Assessing nest building in mice. Nat Protoc. 2006; 1:1117-19. https://doi.org/10.1038/nprot.2006.170 PMID:17406392 
A
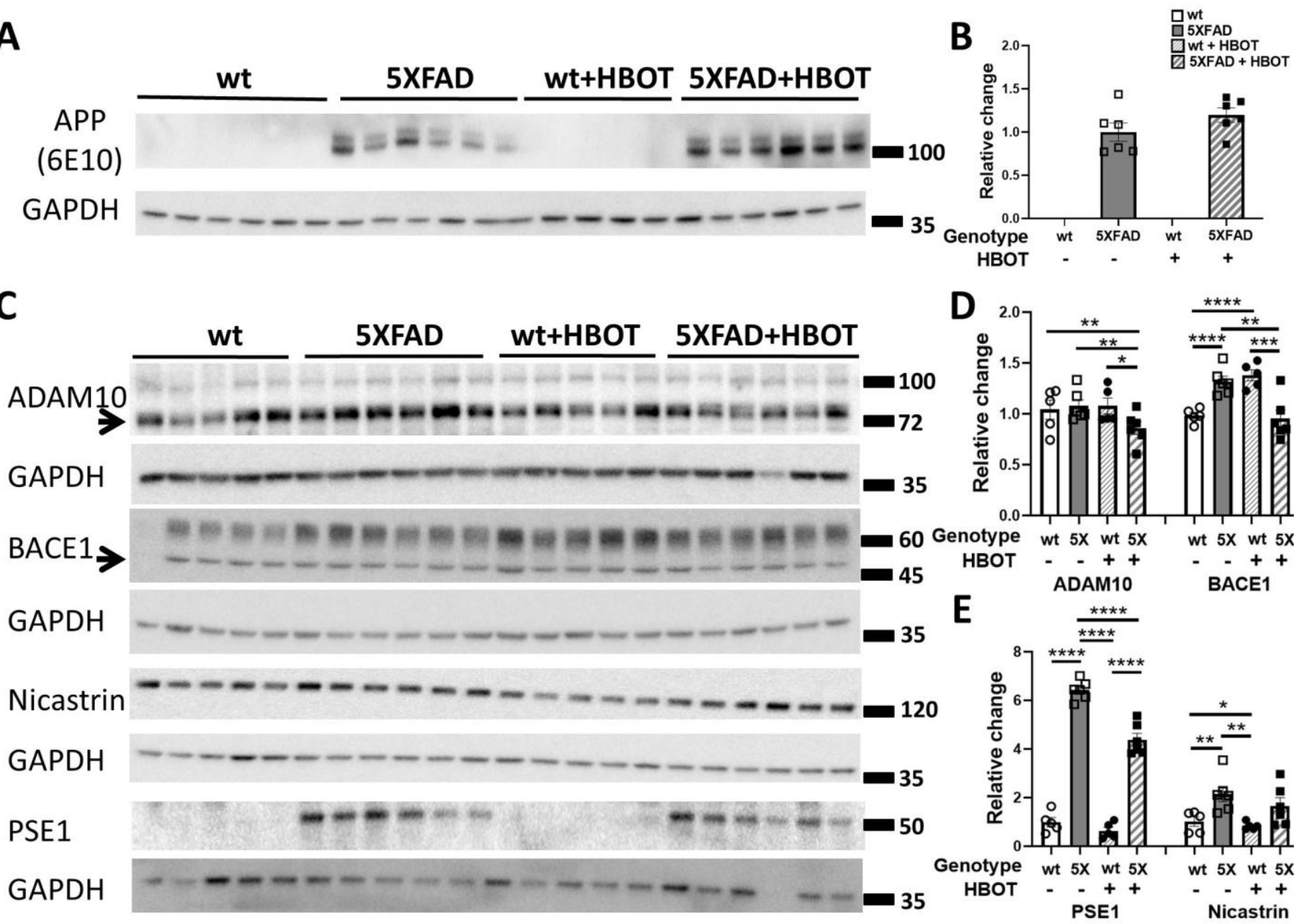

$\mathbf{F}$
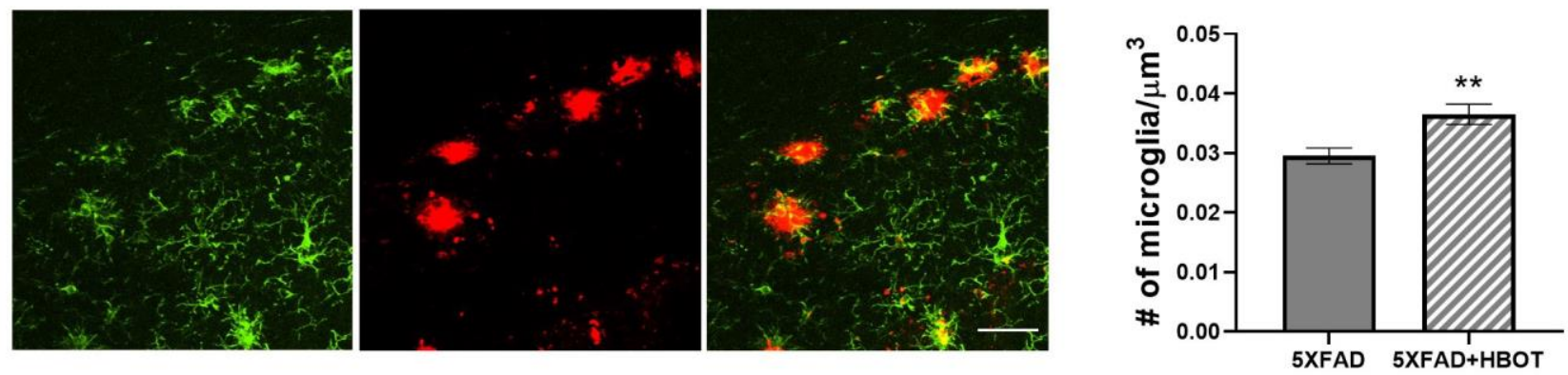

Supplementary Figure 1. Western blots of proteins involved in the APP processing pathway in hippocampi extracted from HBO-treated and control 5XFAD mice and wt littermates. (A) Representative immunoblots of the full APP protein detected by 6 E10 antibodies. (B) Quantification of western blots in (A), presented as percentages of levels in 5XFAD controls, normalized to GAPDH levels $(n=$ 4-5/group). (C) Representative immunoblots of APP-processing enzymes (ADAM10 and BACE1) and proteins comprising the $\gamma$-secretase complex (PSE1 and nicastrin). (D, E) Quantification of the western blots in (C), presented as percentages of levels in wt controls, normalized to GAPDH levels (ADAM10: -37.67\%, $\mathrm{P}=0.0082$; BACE1: $-18.16 \%, \mathrm{P}=0.0011$; PSE: $-25.62 \%, \mathrm{P}<0.000001 ; \mathrm{n}=4-5 /$ group). Two-way ANOVA and post-hoc Fisher LSD tests were performed. (F). Values represent means \pm SEM. $* P<0.05, * * P<0.01, * * * P<0.001, * * * * P<0.0001$. On the left panel, representative images of microglia (Iba-1 staining, green) and plaques (anti-A 4 G8 staining, red) in the hippocampal CA1 of a 5XFAD mouse. Scale bar $40 \mu \mathrm{m}$. On the right panel, quantification of the number of plaque-associated microglia normalized to plaque size $\left(\mu \mathrm{m}^{3}\right)$ in control ( $\mathrm{N}=1108$ plaques) and HBOT 5XFAD ( $\mathrm{N}=907$ plaques) mice ( $\mathrm{n}=5$ per group). 


\section{A}

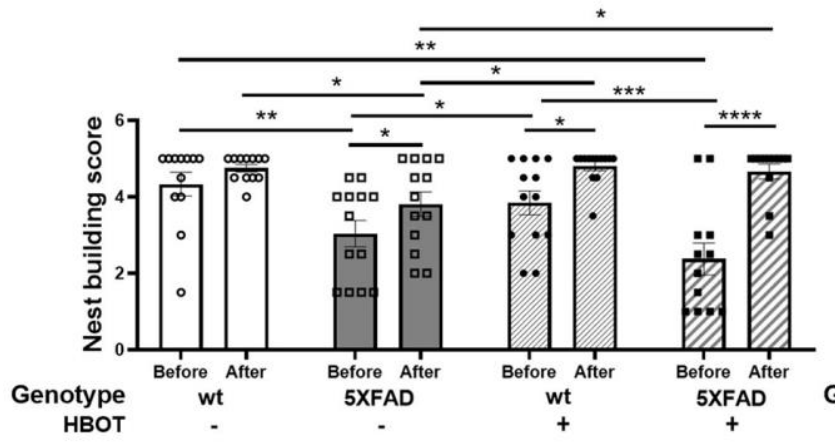

C

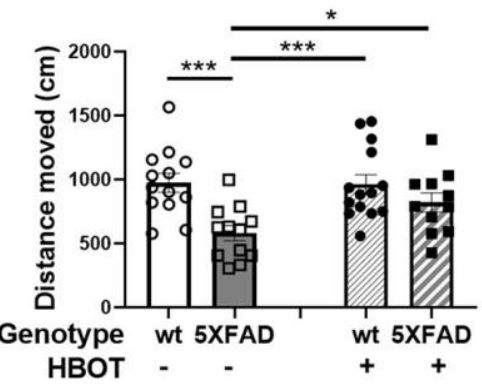

B
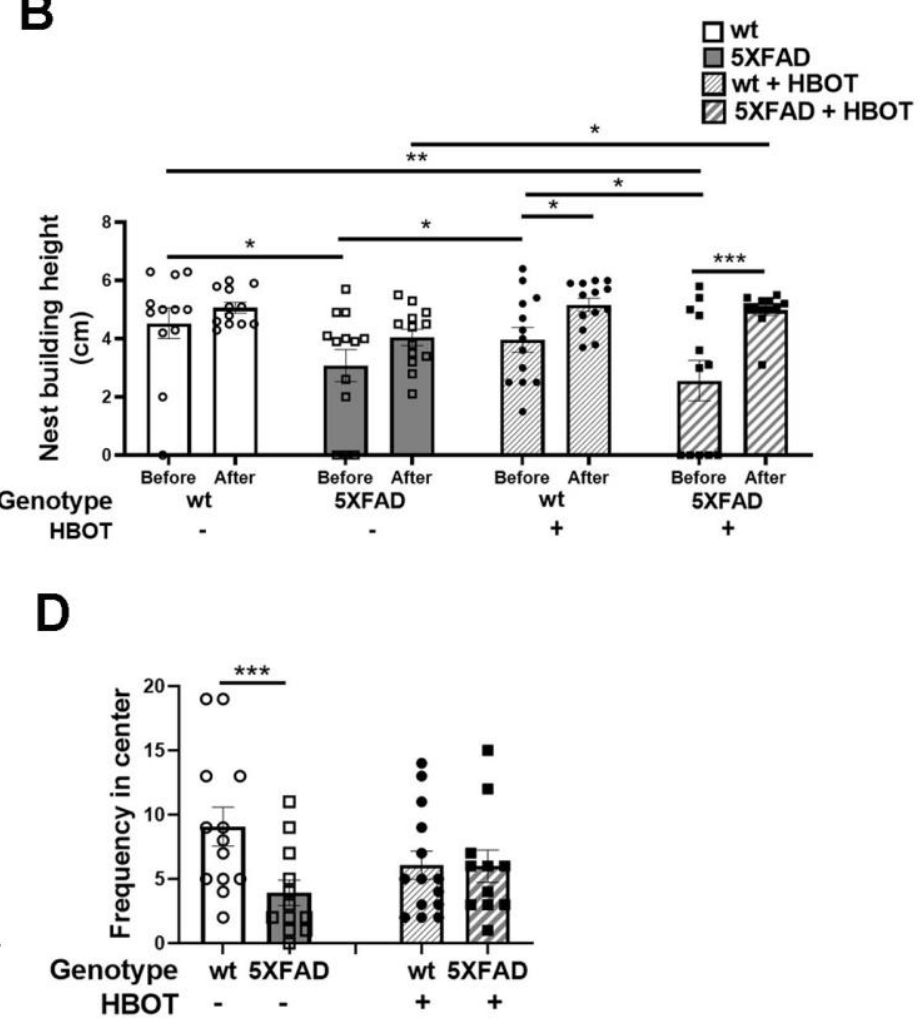

Supplementary Figure 2. HBOT improves performance of 5XFAD in behavioral tasks. Overnight nest building was assessed by nest building score (A) and height (B) before and after a month of HBO or control normobaric treatment of 5XFAD mice and their wt littermates. (C, D) In the open field test, HBO-treated 5XFAD mice show higher locomotive activity than control 5XFAD mice, as demonstrated by distances covered (C). No changes were observed between HBO-treated 5XFAD mice and control mice in terms of navigation in the open field, as reflected by the number of times the center of the arena was crossed (D). Values represent means \pm SEM. ${ }^{*} P<0.05,{ }^{* *} P<0.01, * * *$ $P<0.001, * * * * P<0.0001$.
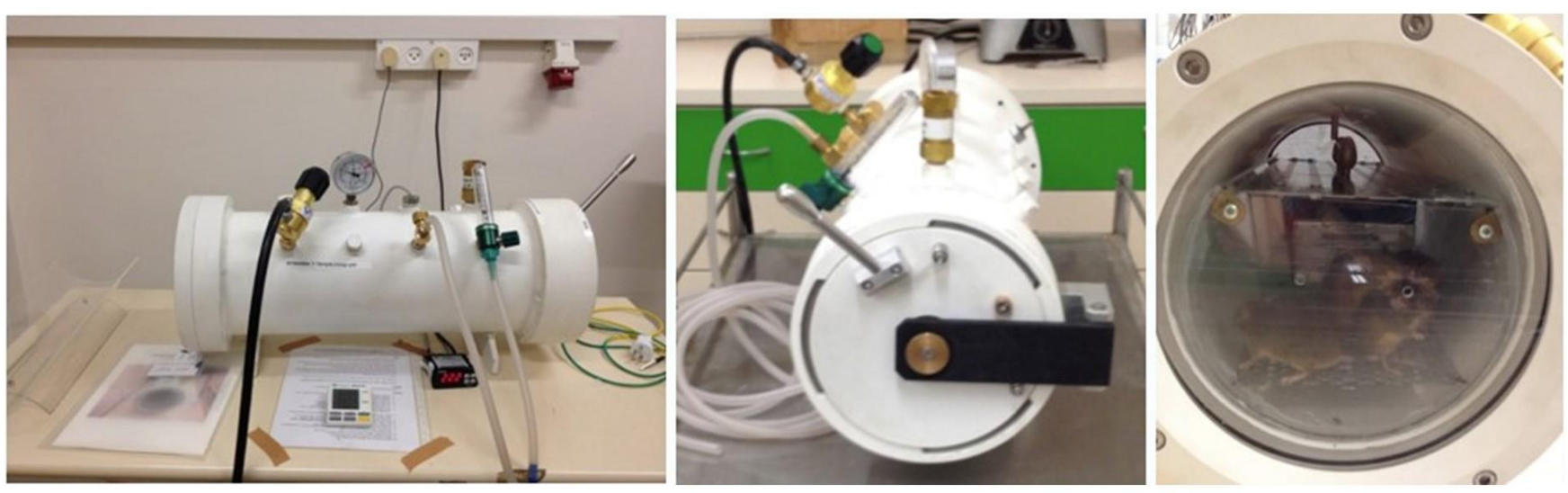

Supplementary Figure 3. Hyperbaric oxygen therapy chamber for small animals. A custom-made chamber for small animals was used to expose 5XFAD mice to HBOT. Oxygen levels in the chamber reached saturation of $\geq 96 \%$, as measured by an oxygen analyzer (model 320BRC, Teledyne Analytical Instruments). Left: front view; middle: side view; right: side view with open door. 


\section{Supplementary Table}

Supplementary Table 1. List of antibodies used for this research.

\begin{tabular}{|c|c|c|c|}
\hline Antibody & Application & Source & Dilution \\
\hline Biotin-conjugated anti-A $\beta$ mouse $\mathrm{mAb}(4 \mathrm{G8})$ & IHC & Covance, SIG-39240 & $1: 200$ \\
\hline $\begin{array}{l}\text { FITC conjugated mouse anti- smooth muscle } \\
\text { actin }(\alpha-S M A\end{array}$ & IHC & Sigma-Aldrich, F3777 & $1: 1,000$ \\
\hline Streptavidin-conjugated goat anti-rabbit Ab & IHC & Invitrogen, S11226 & $1: 1,000$ \\
\hline 488-conjugated goat anti- rabbit & IHC & Jackson ImmunoResearch Laboratories & $1: 1,000$ \\
\hline Rabbit anti- Iba1 & IHC & WAKO, 019-19741 & $1: 700$ \\
\hline HRP- conjugated Goat anti-rabbit Ab & WB & $\begin{array}{c}\text { Jackson ImmunoResearch Laboratories, } \\
111-035-144\end{array}$ & $1: 10,000$ \\
\hline HRP- conjugated Goat anti-mouse Ab & WB & $\begin{array}{c}\text { Jackson ImmunoResearch Laboratories, } \\
115-035-003\end{array}$ & $1: 15,000$ \\
\hline Mouse anti-GAPDH & WB & Abcam, ab9484 & $1: 1,000$ \\
\hline Rabbit anti-ADAM10 pAb & WB & Abcam, ab1997 & $1: 500$ \\
\hline Rabbit anti-BACE1 & WB & Sigma-Aldrich, B0681 & $1: 1,000$ \\
\hline Rabbit anti-Nicastrin $\mathbf{m A b}$ & WB & Cell Signaling D65G7 \#9447 & $1: 5,000$ \\
\hline Mouse anti-Presenilin 1 mAb & WB & Chemicon, Ab 5232 & $1: 500$ \\
\hline Rabbit anti Insulin degrading enzyme & WB & Abcam, ab32216 & $1: 1,000$ \\
\hline $\begin{array}{l}\text { Rabbit anti- Low density lipoprotein } \\
\text { receptor- related protein } 1\end{array}$ & WB & Abcam, ab92544 & $1: 1,000$ \\
\hline
\end{tabular}

